\title{
Influence of Strong and Weak Alkaline Medium on Microstructural and Morphological Investigation of Surfactant Based Synthesis of CdO Nanorods
}

Prakash Thangaraj ( $\sim$ prakash_nano@rediffmail.com )

KPR Institute of Engineering and Technology https://orcid.org/0000-0001-6998-4835

D. Murugesan

Bharathiar University

K. Ramakrishnan

UKF College of Engineering and Technology Department of Civil Engineering

Original Research

Keywords: nanorods, nanoparticles, sodium dodecyl benzene sulphonate, texture coefficient

Posted Date: February 15th, 2021

DOI: https://doi.org/10.21203/rs.3.rs-194225/v1

License: (c) (i) This work is licensed under a Creative Commons Attribution 4.0 International License.

Read Full License 


\title{
Influence of strong and weak alkaline medium on microstructural and morphological investigation of surfactant based synthesis of $\mathrm{CdO}$ nanorods
}

\author{
T. Prakash ${ }^{\mathrm{a}, \mathrm{b}^{*}}$, D. Murugesan ${ }^{\mathrm{c}}$, K. Ramakrishnan ${ }^{\mathrm{d}}$ \\ ${ }^{a}$ School of Chemistry and Chemical Engineering, Shandong University, Jinan, P.R.China 250100. \\ ${ }^{b}$ Department of Physics, KPR Institute of Engineering and Technology, Coimbatore-641 407, \\ Tamilnadu, India. \\ ${ }^{c}$ Department of Nano-science and Technology, Bharathiar University, Coimbatore-641 046, \\ Tamilnadu, India. \\ ${ }^{d}$ Department of Civil Engineering, UKF College of Engineering and Technology, Parippally, \\ Kollam-691302, Kerala, India.
}

\begin{abstract}
A noval microwave irradiated wet chemical method was adopted to prepare cadmium oxide nanostructures by using sodium dodecyl benzenesulphonate (SDBS) as surfactant in presence of strong and weak $0.1 \mathrm{M}$ alkaline medium $\left(\mathrm{NaOH}\right.$ and $\left.\mathrm{NH}_{4} \mathrm{OH}\right)$. The X-ray diffraction measurement shows that the particle is crystallized in the cubic phase, average grain size of the samples are found to be in the range $54 \mathrm{~nm}$ for $\mathrm{NH}_{4} \mathrm{OH}$ reagant and $60 \mathrm{~nm}$ for $\mathrm{NaOH}$ reagent. The XRD pattern value based lattice constant, dislocation density, X-ray density, specific surface area, microstrain-Williamson Hall and texture coefficient have been calculated. The surface functionality of the samples were analysed by using fourier transform infrared spectroscopy. The ultra visble transmittance and K-M plot analysed from the diffuse reflection spectra and photoluminescence spectra also been calculated. The morphological changes of cadmium oxide nanostructures with strong and weak $0.1 \mathrm{M}$ alkaline medium are clearly recored through transmission electron miscroscopy. The reaction mechanism confirms that the experiment carried out in presence of $0.1 \mathrm{M} \mathrm{NaOH}$ shows rod shaped nanostructures through four step mechanism such as hydaration, intermediate formation, metal hydroxide formation and the formation of metal oxide.
\end{abstract}

Keywords: nanorods, nanoparticles, sodium dodecyl benzene sulphonate, texture coefficient.

*Corresponding author (Dr. T. Prakash) e-mail: prakash_nano@rediffmail.com 


\section{Introduction}

Metal oxide nanoparticles are playing major role in wide range of recent technologies. Nowadays all the nanotechnologiest and researchers are showing much interest to investigate the size dependent properties of metal oxide nanoparticles for their promising applications in gas sensors, supercapacitors, computer memory, device fabractions, photocatlytic and antimiocrobial activites [1-4]. Smaller in size and higher in surface area is one of the important parameter to select the metal oxide nanoparticle for their suitable applications. In recent days so many metal oxide nanoparticles like $\mathrm{ZnO}, \mathrm{CuO}, \mathrm{SnO}_{2}, \mathrm{TiO}_{2}$, and $\mathrm{MoO}_{3}$, etc., are synthesized and reported by so many researchers [5-7]. Cadmium oxide (CdO) nanoparticles are also a promising material for multifunctional applications such as sensors, solar cells and photodetectors with their smaller engrgy band gap, low resistivity and high transmission [8]. By vapour phase transport, solvothermal methods, microemulsion and template-assisted, $\mathrm{CdO}$ nanostructures can be synthesized $[9,10]$. These methods, however, require high temperatures, huge investments, multi-step development, sophisticated facilities for instruments, etc $[11,12]$. Hence, a simple cost effect synthesis of metal oxide nanostructures is very challenging task [13].

Among these techniques, microwave-assisted hydrothermal process by surfactants or caping agents by a one-step template-free growth develops different morphology, small particle size, high purity and short reaction time, arbitrary particle shapes [14]. Most of the literatures reports the determination of structure type, bandgap and grain size for $\mathrm{CdO}$ nanostructures [15]. The quantitative crystalline microstructural parameters for $\mathrm{CdO}$ nanoparticle variations developed by microwave-assisted hydrothermal process are analysed using X-ray intensity [16]. The quantitative determination of both texture (polar distribution) and morphology (temperature of nano-rods) of $\mathrm{CdO}$ nanoparticles in the case of microstrain, 
dislocation density, specific surface area, X-ray density etc.can be analysed using simple Xray powder diffraction $[17,18]$.

This presesent study deals with the preparation of CdO nanostructures using SDBS as a surfactant in the presence of $0.1 \mathrm{M}$ strong $(\mathrm{NaOH})$ and weak alkaline $\left(\mathrm{NH}_{4} \mathrm{OH}\right)$ medium. The effects of surfactant and alkaline medium on structural and surface morphological behaviour of CdO nanostructures were analysed using XRD, FTIR, UV, PL, SEM and TEM. Also, determination of different microstructural parameters such as favourable orientation, particle size, RMS strain, texture coefficient etc, is reported for CdO nanostructure by X-ray line profile analysis, UV bandgap, photoluminescence properties been performed.

\section{Experimental Procedure}

\subsection{Materials}

Analytical grade of Cadmium acetate $\left(\mathrm{Cd}\left(\mathrm{CH}_{3} \mathrm{COO}\right)_{2} \cdot 2 \mathrm{H}_{2} \mathrm{O}\right)$, SDBS, $\mathrm{NH}_{4} \mathrm{OH}$ and $\mathrm{NaOH}$ were purchased from SD-fine chemicals, India. All the chemicals were used without further purification. Double distilled water was used for performing the experiments.

\subsection{Synthesis of CdO Nanostructure}

$0.1 \mathrm{M}$ of cadmium solution was prepared by dissolving known volume of cadmium acetate in double distilled water. The surfactant SDBS was prepared as a solution by disolving $4 \mathrm{~g}$ of SDBS with $50 \mathrm{ml}$ double distilled water. Both the solutions were taken in 1:1 proportion and the intial $\mathrm{pH}$ of the mixture is adjusted to 9.0 by the addition of $0.1 \mathrm{M} \mathrm{NH}_{4} \mathrm{OH}$. The mixture is stirred well for two hours and then placed in microwave oven (Model No. IFB, 17PG1S, microwave 700W, input range 210-230 V-ac 50Hz, microwave radiation frequency $2.45 \mathrm{GHZ}$, Power up to $1 \mathrm{KW}$ ), for 3 minutes. The hot mixture is kept aside for an hour for the complete precipitation. The residual precipitate is filtered and the filtrant is used to mesure the final $\mathrm{pH}$. The filtrate is washed with double distilled water until its filtrant achieves neutral $\mathrm{pH}$. The neutralized filtrate or precipitate is known as pure cadmium 
hydroxide, $\mathrm{Cd}(\mathrm{OH})_{2}$ and it is rinsed with ethanol for the removal of residual impurities if any. The purified $\mathrm{Cd}(\mathrm{OH})_{2}$ is weighed and annealed at $300{ }^{\circ} \mathrm{C}$ for three hours for the development of $\mathrm{CdO}$. A similar experimental procedure was repated for the synthesis of $\mathrm{CdO}$ nanorods in presence of $0.1 \mathrm{M} \mathrm{NaOH}$ with the initial $\mathrm{pH}$ of 11.0 (Scheme 1). The final product is stored in air tight container and kept it in dessicator for further investigations.

\subsection{Characterization}

X-ray diffraction data (XRD) were recorded using Bruker (AXS D8 Advance) diffractometer with $\mathrm{CuK}_{\alpha}$ radiation $(\lambda=1.5406 \AA)$ operating at $40 \mathrm{kV}$ and $30 \mathrm{~mA}$. Fourier transform infrared spectroscopy (FT-IR) spectra were recorded using Bio Rad Spectrometer (Mod. FTS-7) in $\mathrm{KBr}$ matrix in the range of $400-4000 \mathrm{~cm}^{-1}$. Diffuse reflectance spectroscopy (DRS) spectra were recorded on a Perkin Elmer UV-visible DRS spectrophotometer. Room

temperature photoluminescence (PL) spectra were registered on a spectrofluorimeter Fluorolog (Mod. FL3-11). Scanning electron microscopy (SEM) and energy dispersive X-ray (EDX) analysis were recorded with JEOL Mod. JSM- 6390LV instrument. Transmission electron microscopy (TEM), High resolution transmission electron microscopy (HR-TEM) and selected area electron diffraction (SAED) images were collected by using Philips (Mod. CM 200), electron microscope with an acceleration voltage of $80 \mathrm{kV}$. 


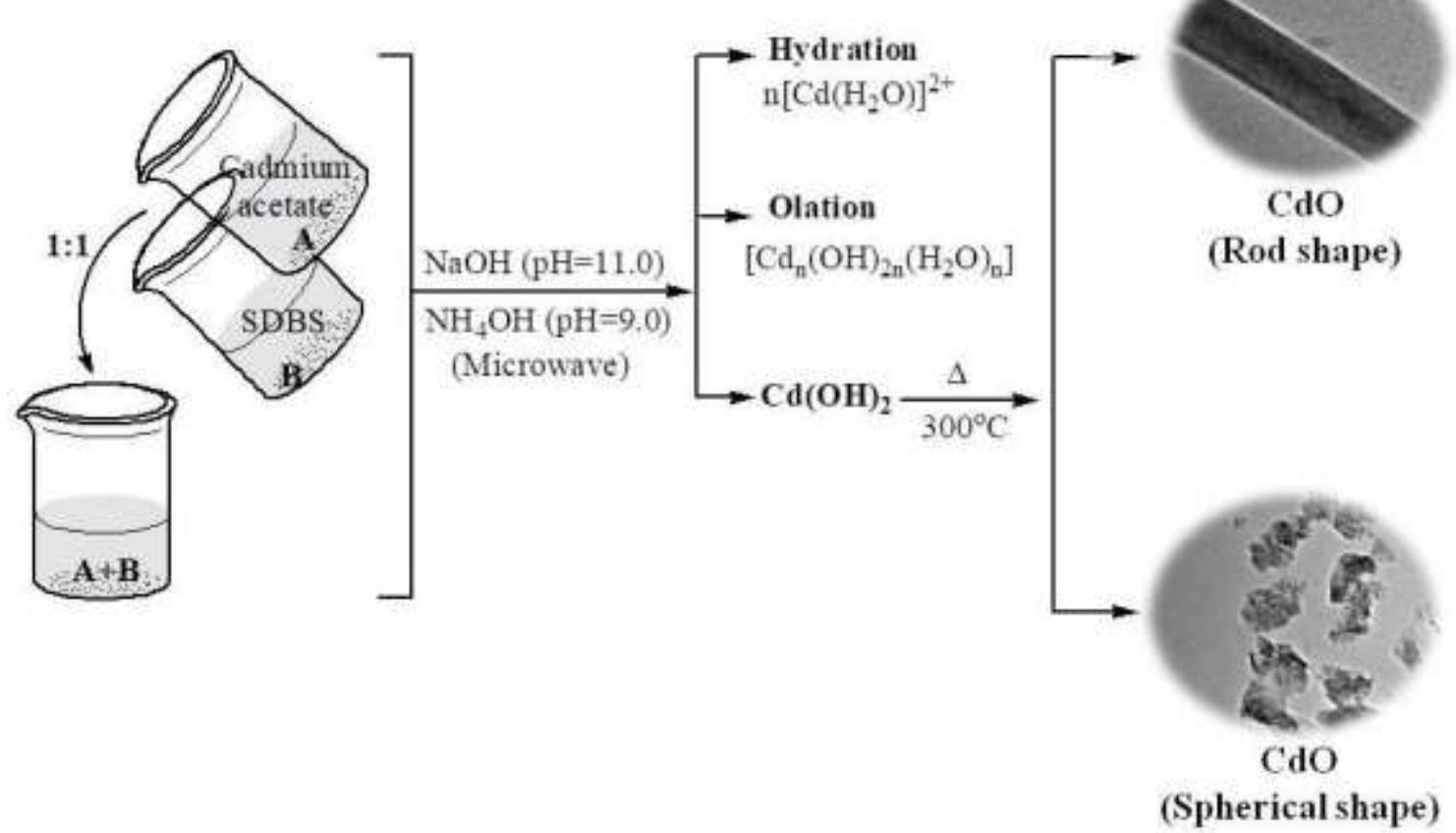

\section{Scheme 1. Schematic representation of synthesis procedure for $\mathrm{CdO}$ nanostructures}

\section{Results and discussion}

\subsection{Structural analysis}

The structural phase composition of $\mathrm{CdO}$ nanostructures prepared using SDBS as a surfactant in presence of strong and weak alkaline medium $\left(\mathrm{NaOH}\right.$ and $\left.\mathrm{NH}_{4} \mathrm{OH}\right)$ has been analysed through XRD pattern (Fig.1). The as prepared CdO nanostructure using SDBS and $0.1 \mathrm{M} \mathrm{NH}_{4} \mathrm{OH}$ samples (see Fig.1(a)) shows multiple (hkl) plans and low crystalline nature. The same sample was annealed at $300{ }^{\circ} \mathrm{C}$ (see Fig.1(b)) and it shows that the (hkl) miller indecies (111), (200), (220), (311) and (222) with sharp peaks. It indicates the improved crystallinity. The indexed profile are well matched with standard JCPDS(05-0640). Similar characteristic peaks were observed in presence of $0.1 \mathrm{M} \mathrm{NaOH}$ samples (Fig.1(c-d)). But, the annealing have engendered identical crystallinity in presence of $\mathrm{NH}_{4} \mathrm{OH}$ and $\mathrm{NaOH}$ with SDBS. Debye-scherer's equation was used to estimate the crystillite size (D) and lattice 
parameter (a) of the as prepared and annealed $\mathrm{CdO}$ nanostructures were calculated using the formula.

$$
D=\frac{K \lambda}{\beta \cos \theta}
$$

Where, $\mathrm{D}$ is the crystalline size, $\lambda$ is the wavelength, $\beta$ is the full width at half maximum of a diffraction peak measured in radians and $\theta$ is the Bragg's angle.

$$
a^{2}=d^{2}\left(h^{2}+k^{2}+l^{2}\right)
$$

Where, $(\mathrm{h}, \mathrm{k}, \mathrm{l})$ are the Miller indices, while (d) is the interplanar distances which can be determined by Bragg's law [19].

The estimated structural parameters of the $\mathrm{CdO}$ nanostructures are increased with annealing temperature. The mean crystillite sizes of the samples found to be in the range 59 $\mathrm{nm}$ and $60 \mathrm{~nm}$. It was also observed that lattice constant value is a well matched with theoretical and experimental value of crystalline size and $2 \theta$ value. The dislocations or crystallographic defects interrupt the dislocation lines regular patterns. Dislocation densities are calculated from particle size and strain values. The data indicated that the migration density describes the concentration of crystalline deficits which is high. The crystallographic properties were highly affected by the presence of dislocation density. The dislocation density using crystalline size value (D) has been determined using the williamson and smallman's formula [20].

$$
\delta=\frac{1}{D^{2}}\left(10^{14} \text { lines } / m^{2}\right)
$$

The volume-mass density is a powerful tool used to characterize any material (of any form bulk, thin films or powder) and its ability also to explore any changes in the crystal structure of the crystalline material. It can be calculated theoretically from X-ray diffractograms using the following equation: where $n$ is the number of atoms per unit cell, $\mathrm{Mw}$ is the molecular weight, $\mathrm{V}$ is the volume of the unit cell and NA is Avogadro's 
number. The theoretical density is also known as X-ray density because it requires information about the crystal structure of the studied compound which are deduced from Xray diffraction analysis. Theoretical density is sensitive to the crystal structure unlike the bulk density [21].

$$
\rho_{x}=\frac{n \cdot M_{w}}{N_{a} \cdot V}\left(\mathrm{~g} / \mathrm{cm}^{3}\right)
$$

Specific surface area (SSA) describes the properties of the material and determines its type and structure. Practically this quantity may be used for analyzing reactions on surfaces, adsorption and heterogeneity of the sample [22].

$$
S_{a}=\frac{6}{D \times \rho_{x}}\left(10^{5} \mathrm{~cm}^{2} / \mathrm{g}\right)
$$

Where $\mathrm{D}$ is the size of the crystallite and $\rho$ is the density of the used experimental samples. The microstrain was calculated by the Williamson-Hall method. The size of the crystallite can be measured with the help of XRD data value. The slope value of the straight line from the relation between $\beta \cos \theta v s 4 \sin \theta$, in Fig.2(a-b) indicated the microstrain behaviour of the $\mathrm{CdO}$ nanostructure in the studied samples.

$$
\beta \cos \theta=\left(\frac{0.9 \lambda}{D}\right)+(4 \varepsilon \sin \theta)
$$

Further, presence of imperfections in the crystal growth can bring about significant changes in the properties of nanostructures. The imperfections include: crystallite size, dislocation density, strain, W-H plot and lattice distortion leads to formation of strained crystals and have been a very important for the solid state substrate [23-25]. However, the effects of imperfections on annealed temperature $\left(300{ }^{\circ} \mathrm{C}\right)$ are yet to be studied. The quantitative of all samples were correlated with their structure and morphology.

The Texture coefficient $\mathrm{TC}(\mathrm{hkl})$ value of the samples has been calculated from the XRD data using the relation [26], 


$$
\mathrm{TC}=\frac{I(h k l) / I_{o}(h k l)}{\frac{1}{N} \sum_{N} I(h k l) / I_{o}(h k l)}
$$

Where, $\mathrm{I}(\mathrm{hkl})$ is the measured relative intensity of a plane and $\mathrm{I}_{0}(\mathrm{hkl})$ is the standard intensity of the plane taken from the JCPDS data. The value $\mathrm{TC}(\mathrm{hkl})=1$ represents films with randomly oriented crystallites, while higher values indicate the abundance of grains oriented in a given (hkl) direction. The variation of TC for the peaks of the cubic crystal structure is seen to be highest plane (111) for using $300{ }^{\circ} \mathrm{C}$ annealed temperature, which is shown in the Table 1. The Texture coefficient TC [111] value increase in preferred orientation is attributed to the increase in the grain number in this orientation.

The obtained values of the crystalline size, lattice parameters, dislocation density, X-ray density, specific surface area, texture coefficient value of $\mathrm{CdO}$ nanstructure using SDBS surfactant in presence of $0.1 \mathrm{M}$ strong and weak alkaline $\left(\mathrm{NaOH}\right.$ and $\left.\mathrm{NH}_{4} \mathrm{OH}\right)$ medium obtained in Table 1. 

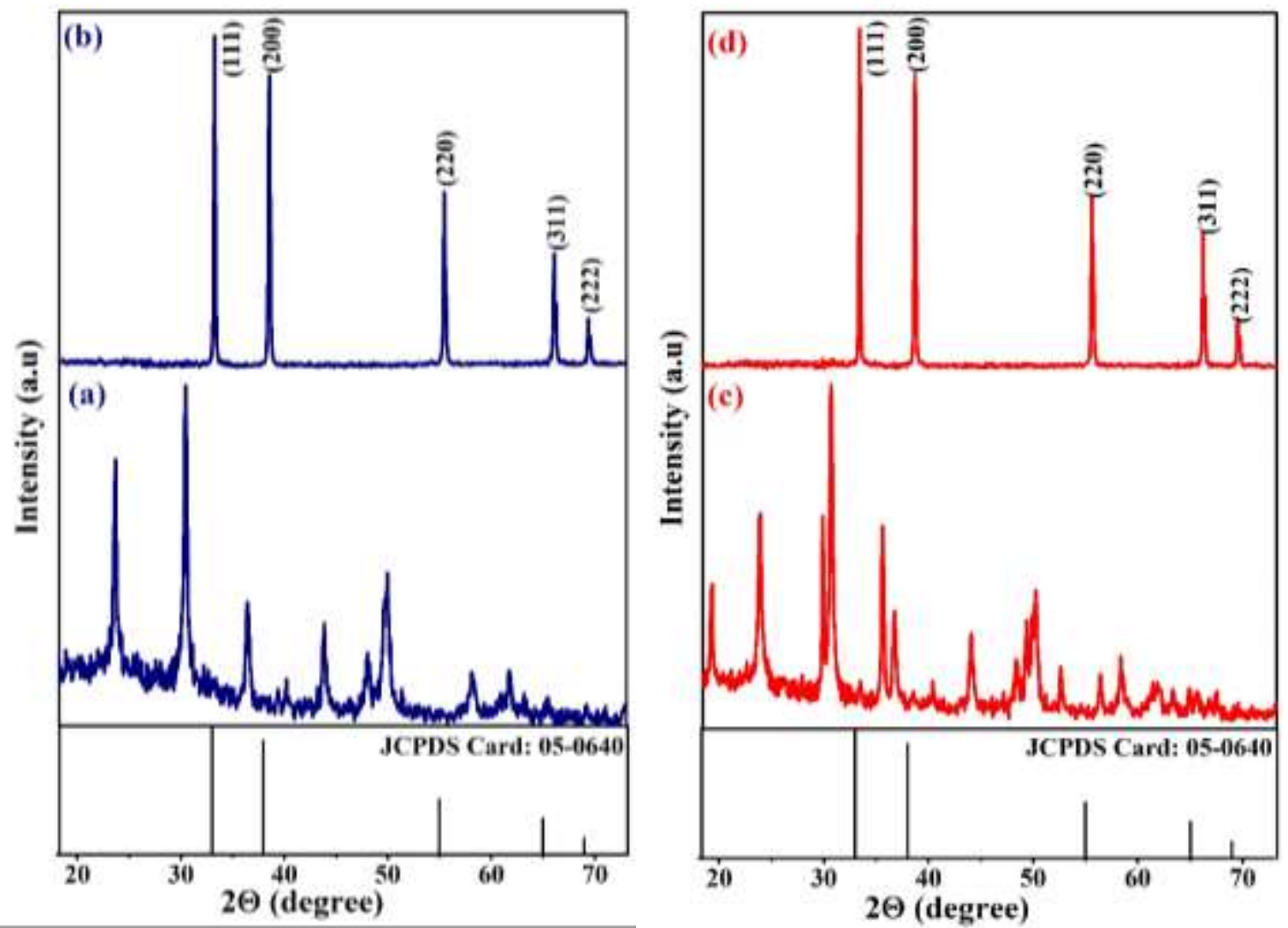

Fig.1 XRD pattern of $\mathrm{Cd}(\mathrm{OH})_{2}$ inpresence of $0.1 \mathrm{M} \mathrm{NH}_{4} \mathrm{OH}$ and $\mathrm{NaOH}(\mathrm{a \& c})$ and $\mathrm{CdO}$ nanostructure inpresence of $0.1 \mathrm{M} \mathrm{NH} \mathrm{NH}_{4} \mathrm{OH}$ and $\mathrm{NaOH}(\mathrm{b} \& d)$.
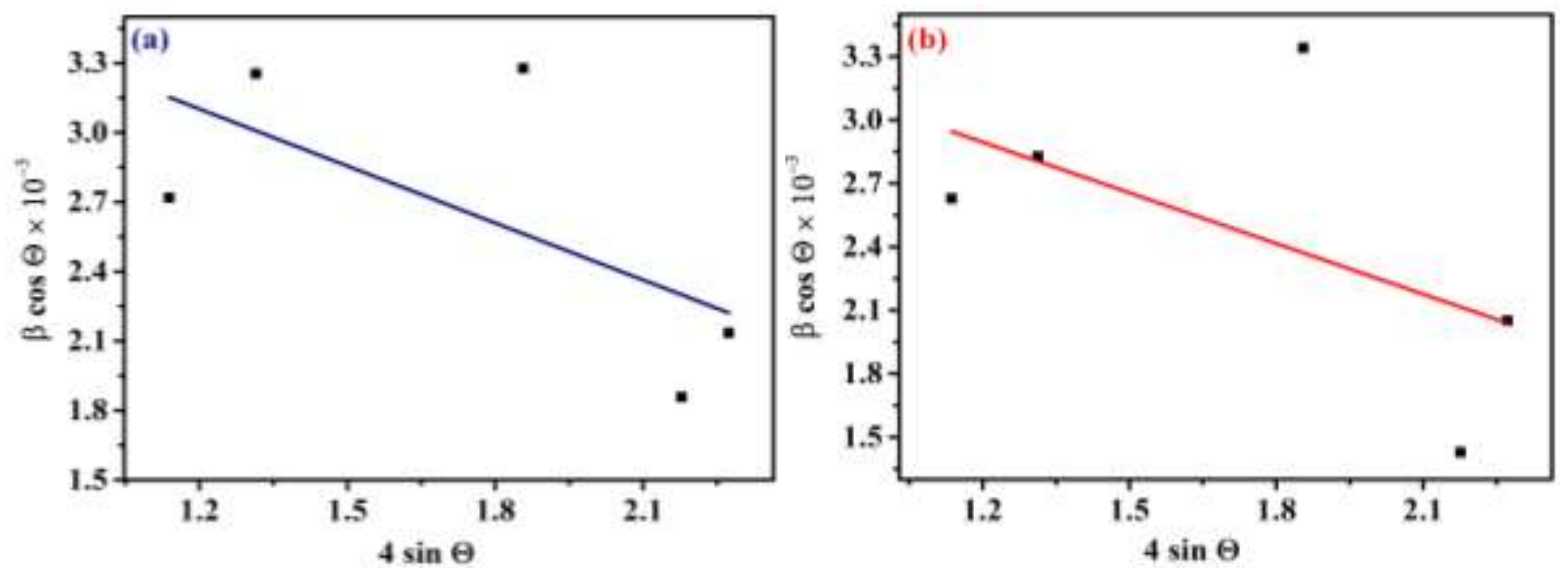

Fig.2 Williamson Hall Plot is indicating line broadening value due to the equipment of CdO nanostructure inpresence of $0.1 \mathrm{M} \mathrm{NH} \mathrm{NH}_{4} \mathrm{OH}$ and $\mathrm{NaOH}(\mathrm{a \& b})$. 
Table 1: XRD parmeters of $\mathrm{CdO}$ nanostructures developed inpresence of $0.1 \mathrm{M}$ strong and weak alkaline medium.

\begin{tabular}{lcc}
\hline \multicolumn{1}{c}{ XRD Parameters } & $\mathbf{N H}_{4} \mathrm{OH}$ & $\mathbf{N a O H}$ \\
\hline Crystalline size (D) nm & 54 & 60 \\
Lattice Parameters $\AA$ (a) & 4.69264 & 4.69625 \\
& $3.93(111)$ & $3.67(111)$ \\
Dislocation Density & $5.63(200)$ & $4.25(200)$ \\
& $5.71(220)$ & $5.93(220)$ \\
X-ray density & 8.2538 & 8.2348 \\
& 1.3461 & 1.2143 \\
Specific surface area & $0.8884(111)$ & $0.8596(111)$ \\
& $0.8869(200)$ & $0.8462(200)$ \\
Texture coefficient & $1.0934(220)$ & $1.0249(220)$
\end{tabular}

\subsection{Functional group analysis}
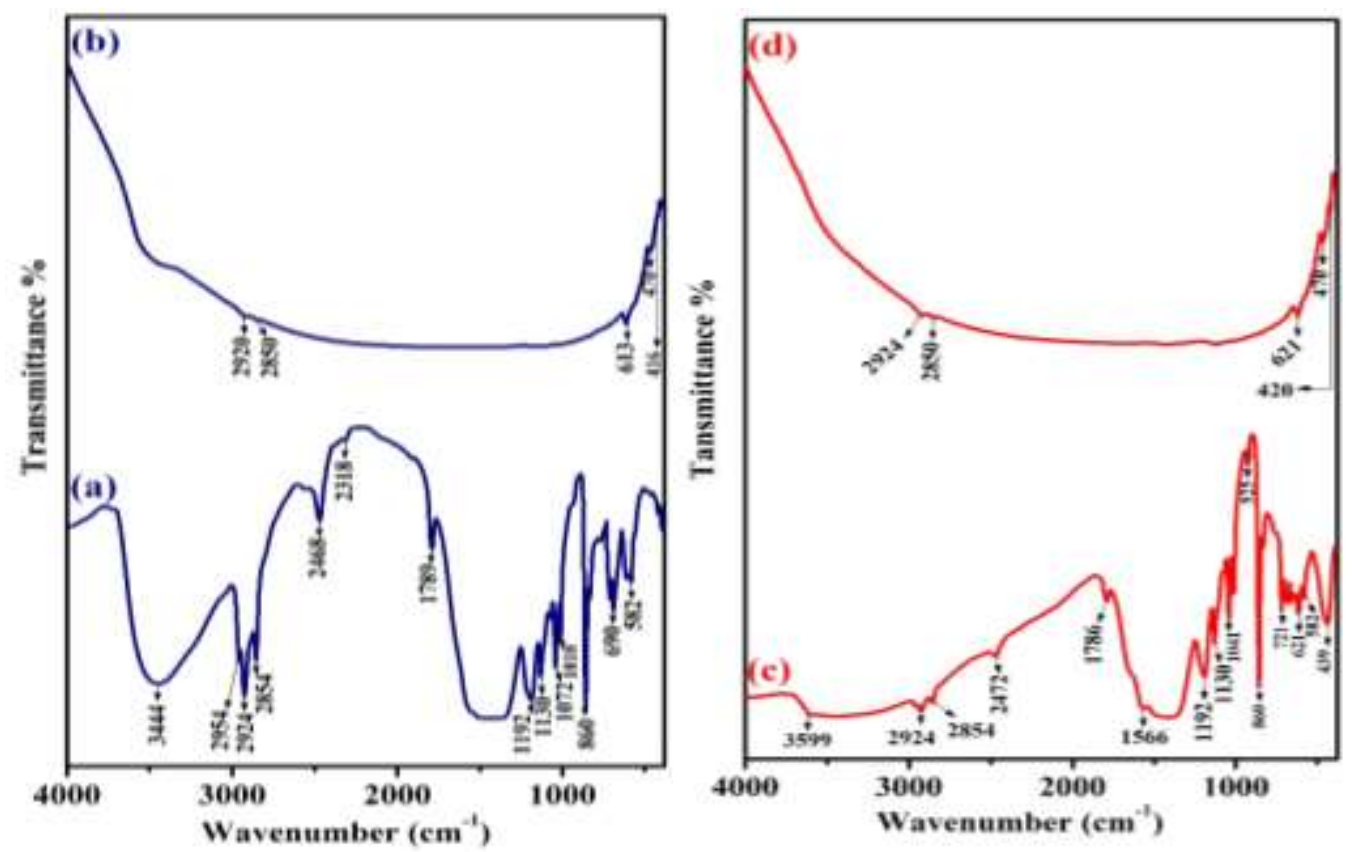

Fig.3 FTIR spectra of $\mathrm{Cd}(\mathrm{OH})_{2}$ inpresence of $0.1 \mathrm{M} \mathrm{NH} \mathrm{NH}_{4} \mathrm{OH}$ and $\mathrm{NaOH}(\mathrm{a \& c})$ and $\mathrm{CdO}$ nanostructure inpresence of $0.1 \mathrm{M} \mathrm{NH} \mathrm{NH}_{4} \mathrm{OH}$ and $\mathrm{NaOH}$ (b\&d). 
Fig.3(a, c) shows the surface functional analysis of $\mathrm{CdO}$ nanostructures in the range between $4000 \mathrm{~cm}^{-1}$ to $400 \mathrm{~cm}^{-1}$. The $\mathrm{O}-\mathrm{H}$ stretching mode of vibration indicates the range between $3444 \mathrm{~cm}^{-1}$ to $3599 \mathrm{~cm}^{-1}$. The $\mathrm{O}-\mathrm{H}$ vibration mode of peaks changes from broad to very sharp (Fig.3a\&c), this quick change of vibration demonstrate that the weak alkaline medium $(\mathrm{pH}=9.0)$ does not support the complete formation of spherical nano particle, however while using strong alkaline medium in presence of $0.1 \mathrm{M} \mathrm{NaOH}(\mathrm{pH}=11.0)$ the particles are transformed to nanorod shaped particles. When $\mathrm{pH}$ value increases in presence of of $0.1 \mathrm{M} \mathrm{NaOH}$, the vibration peak of $\mathrm{C}=\mathrm{O}$ was moved up and down which is also due to the morphological changes observed from TEM images and the symmetric stretching take place $1192 \mathrm{~cm}^{-1}$ to $860 \mathrm{~cm}^{-1}$ [27,9]. This is mainly due to the step-by-step removal of hydrated water molecules from the intermediate complex by $\mathrm{OH}^{-}$ions from sodium hydroxide. This has been confirmed in the reaction mechanism. Fig.3(b\&d) shows O-H stretching mode of vibration peaks observed and it is clearly identified the O-H stretching is broad from flat peaks, when the sample is annealed at $300{ }^{\circ} \mathrm{C}$. Here, the $\mathrm{O}-\mathrm{H}$ stretching mode of vibration can plays a significant role in the morphology changes and it is clearly shows TEM images. The asymmetric stretching mode of vibration of $\mathrm{C}=\mathrm{O}$ was observed $1566 \mathrm{~cm}^{-1}$. Fig.3 (b\&d) shown Cd-O peaks at $613 \mathrm{~cm}^{-1}, 621 \mathrm{~cm}^{-1}$ and $470 \mathrm{~cm}^{-1}$ in the finger print region [28]. The annealing has removed many weak peaks from CdO (Fig.3(b\&d). The FTIR spectrum confirms pure $\mathrm{CdO}$ by the presence of characteristic bands at $416 \mathrm{~cm}^{-1}$ and $420 \mathrm{~cm}^{-}$

1. For conclude from the Fig.3(b\&d) the $\mathrm{pH}$ value increases the vibration band of $\mathrm{CdO}$ increases from $416 \mathrm{~cm}^{-1}$ to $420 \mathrm{~cm}^{-1}$ [10]. This wave number changes point out the morphology of cadmium oxide related to SEM and TEM interpretation.

\subsection{Optical group analysis}

$\mathrm{CdO}$ has been largely investigated for its interesting optical, optoelectronic and sensing properties. Previously, we published many papers about the synthesis of $\mathrm{CdO}$ 
nanomaterials, investigating the effect of synthesis variables on the morphological, microstructural, electrical and optical properties of the obtained products. However, in this paper, we report for the first time, the effect of $0.1 \mathrm{M}$ strong and weak alkaline $(\mathrm{NaOH}$ and $\mathrm{NH}_{4} \mathrm{OH}$ ) medium used in the synthesis of $\mathrm{CdO}$ nanostructures and the evaluation of their morphological, microstructural and optical characteristics. Here, an optical characterization through diffuse reflectance spectroscopy (DRS) and PL for the $\mathrm{CdO}$ nanostructures synthesized has been carried out to evaluate the band gap (Eg) and photoluminescence emissions under a $349 \mathrm{~nm}$ excitation $[29,9]$.

Diffuse reflectance spectroscopy has been often used for assessing the optical quality of materials, giving information on the absorption properties of bulk and thin films samples. The optical properties of $0.1 \mathrm{M}$ strong and weak alkaline $\left(\mathrm{NaOH}\right.$ and $\left.\mathrm{NH}_{4} \mathrm{OH}\right)$ medium samples were measured in the wavelength range of $300-800 \mathrm{~nm}$ at room temperature. The reflectance values recorded were converted to absorbance by application of Kubelka-Munk function [30], expressed by the following relation:

$$
\begin{aligned}
& (\alpha . h v)^{1 / 2}=A\left(h v-E_{g}\right) \\
& F(R)=\frac{K}{S}=\frac{(1-R)^{2}}{2 R}
\end{aligned}
$$

The bandgap was estimated by means of a Tauc plot of the Kubelka-Munk function $\mathrm{F}(\mathrm{R})$, considering the indirect bandgap semiconductor nature of $\mathrm{CdO}$ nanostructures. For an indirect semiconductor, the Tauc plot is described by eqn (8), where $\alpha$ is the absorption coeficient, $\mathrm{h} v$ is the photon energy, $\mathrm{A}$ is a constant and $\mathrm{E}$ is the energy gap. However, for a powder sample, absorption can be estimated as an approximation from the Kubelka-Munk function eqn (9), where $\mathrm{k}$ and $\mathrm{s}$ are the absorption and scattering coefficients respectively, and $\mathrm{R}$ represents the diffuse reflectance. Even though this procedure tends to underestimate the real bandgap energy of the material, giving the so-called optical bandgap, it was 
demonstrated to be effective in many cases. From the plot of $(F(R) \cdot h v)^{1 / 2}$ versus the energy $(\mathrm{h} v)$, the bandgap energy $\mathrm{E}$ is estimated by extrapolating the intercept of the fitted straight line at $F(R)=0$. As evidenced in the inset of Fig.4(a) an optical bandgap of 0.1M weak alkaline $\mathrm{NH}_{4} \mathrm{OH}$ medium $(1.8 \mathrm{eV})$ and Fig.4(b) $0.1 \mathrm{M}$ strong alkaline medium $\mathrm{NaOH}(2.0 \mathrm{eV})$ was estimated. As the energy band gap is known to increase as particle size of the semiconductor nanomaterials decreases, the higher value of band gap recorded for the $\mathrm{NH}_{4} \mathrm{OH}$ samples is a confirm of the presence of nanostructures of reduced size [8].

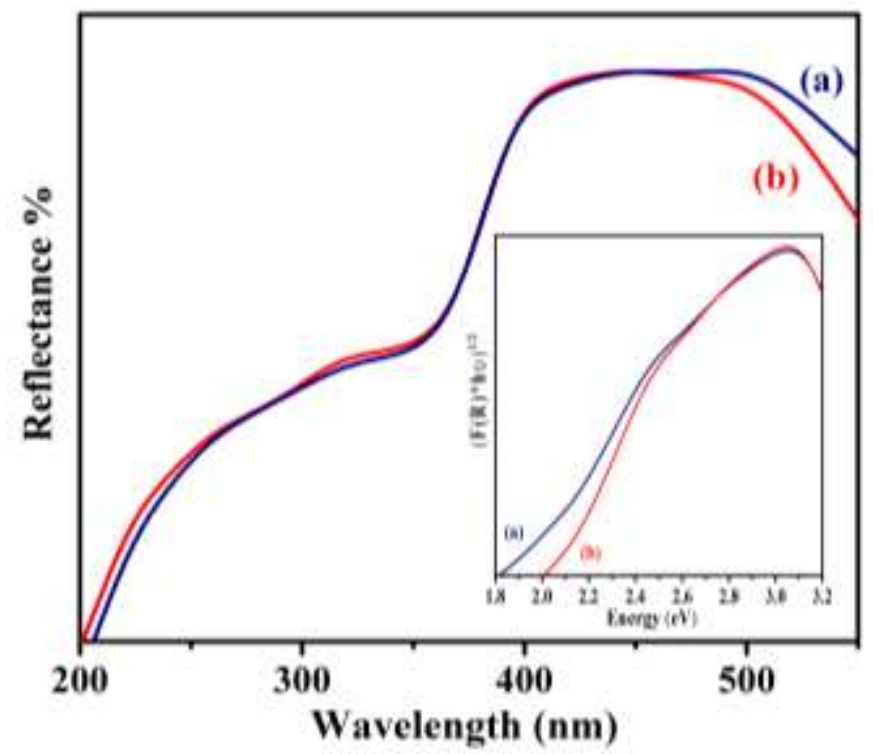

Fig.4 UV spectra of $\mathrm{CdO}$ nanostructure inpresence of $0.1 \mathrm{M} \mathrm{NH} \mathrm{NH}_{4} \mathrm{OH}$ and $\mathrm{NaOH}(\mathrm{a \& b})$.

Photoluminescence (PL) characteristics of $0.1 \mathrm{M}$ strong and weak alkaline $(\mathrm{NaOH}$ and $\mathrm{NH}_{4} \mathrm{OH}$ ) medium samples have been also investigated. Room temperature PL spectra are shown in Fig.5(a-b). The weak alkaline $\mathrm{NH}_{4} \mathrm{OH}$ medium sample exhibits a high intensity emission peak at $\sim 453 \mathrm{~nm}$. In the PL emission spectrum of strong alkaline $\mathrm{NaOH}$ medium sample is instead evidenced the strong UV emission peak $\sim 458 \mathrm{~nm}$. This behaviour is likely due to the different morphology of the samples. In fact, it is well known that the shape and size of the nanostructures are important factors which play a critical role in determining the intensity of the PL emissions. In case of $0.1 \mathrm{M}$ strong and weak alkaline $\left(\mathrm{NaOH}\right.$ and $\left.\mathrm{NH}_{4} \mathrm{OH}\right)$ medium sample, the formed agglomerates are somewhat thicker and this hinders the radiation 
to diffuse towards the surface, which resultsin a decrease in the intensity of the blue emission peaks $[31,9]$.

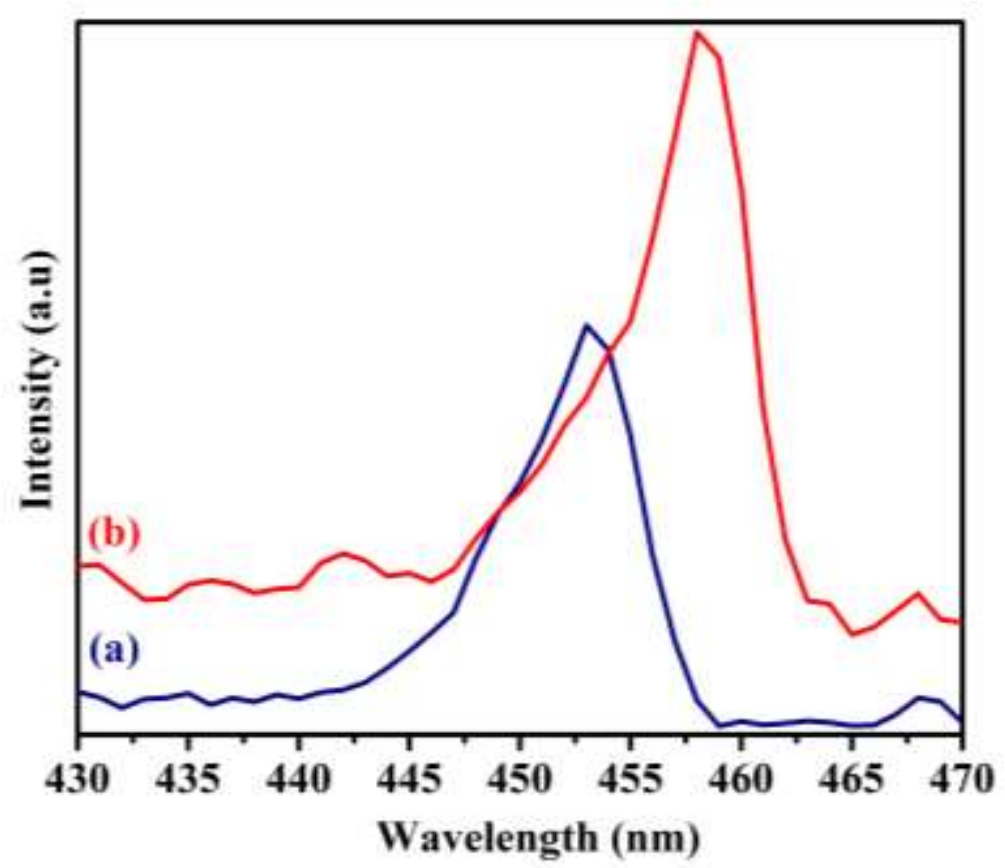

Fig.5 PL spectra of $\mathrm{CdO}$ nanostructure inpresence of $0.1 \mathrm{M} \mathrm{NH} \mathrm{NH}_{4} \mathrm{OH}$ and $\mathrm{NaOH}(\mathrm{a \& b})$.

\subsection{Morphology analysis}

Scanning electron microscopy (SEM) analysis has been obtained great surface morphology change of using surfactant SDBS with CdO nanostructures in presence of $0.1 \mathrm{M}$ strong and weak alkaline $\left(\mathrm{NaOH}\right.$ and $\left.\mathrm{NH}_{4} \mathrm{OH}\right)$ medium. Fig.6(a-b) shows the SEM image of $\mathrm{NH}_{4} \mathrm{OH}$ annealed at $300{ }^{\circ} \mathrm{C}$. The pictures of SDBS surfactant capped with $\mathrm{CdO}$ nanostructures in presence of $0.1 \mathrm{M} \mathrm{NH} \mathrm{NH}_{4} \mathrm{OH}$ do not show any clear surface morphology, however these images says that the $\mathrm{CdO}$ nanoparticles smaller agglomerated with not uniform sphere look. The SEM images of SDBS capped CdO nanorods in presence of 0.1M $\mathrm{NaOH}$ annealed at $300{ }^{\circ} \mathrm{C}$ shown in Fig.6(c-d). In presence of $0.1 \mathrm{M} \mathrm{NaOH}$, the $\mathrm{CdO}$ nanoparticles appearance is agglomerated tiny nanorods. Hence, the results confirm that, when using $0.1 \mathrm{M}$ strong alkaline $\mathrm{NaOH}$ medium the smaller spherical particles altered to nanorods. The size of the $\mathrm{CdO}$ nanoparticle is $90 \mathrm{~nm}$ to $150 \mathrm{~nm}$. The microwave synthesized 
$\mathrm{CdO}$ nanostructures is obtained remarkable changes in morphology, when using different coreagents with SDBS surfactant. Morphology results are highlighted that $0.1 \mathrm{M} \mathrm{NaOH}$ change abruptly from sphere to rod like nanostructures. This kind of size and shape change of metal oxide nanostructures are welcomes to optical properties $[32,8]$.
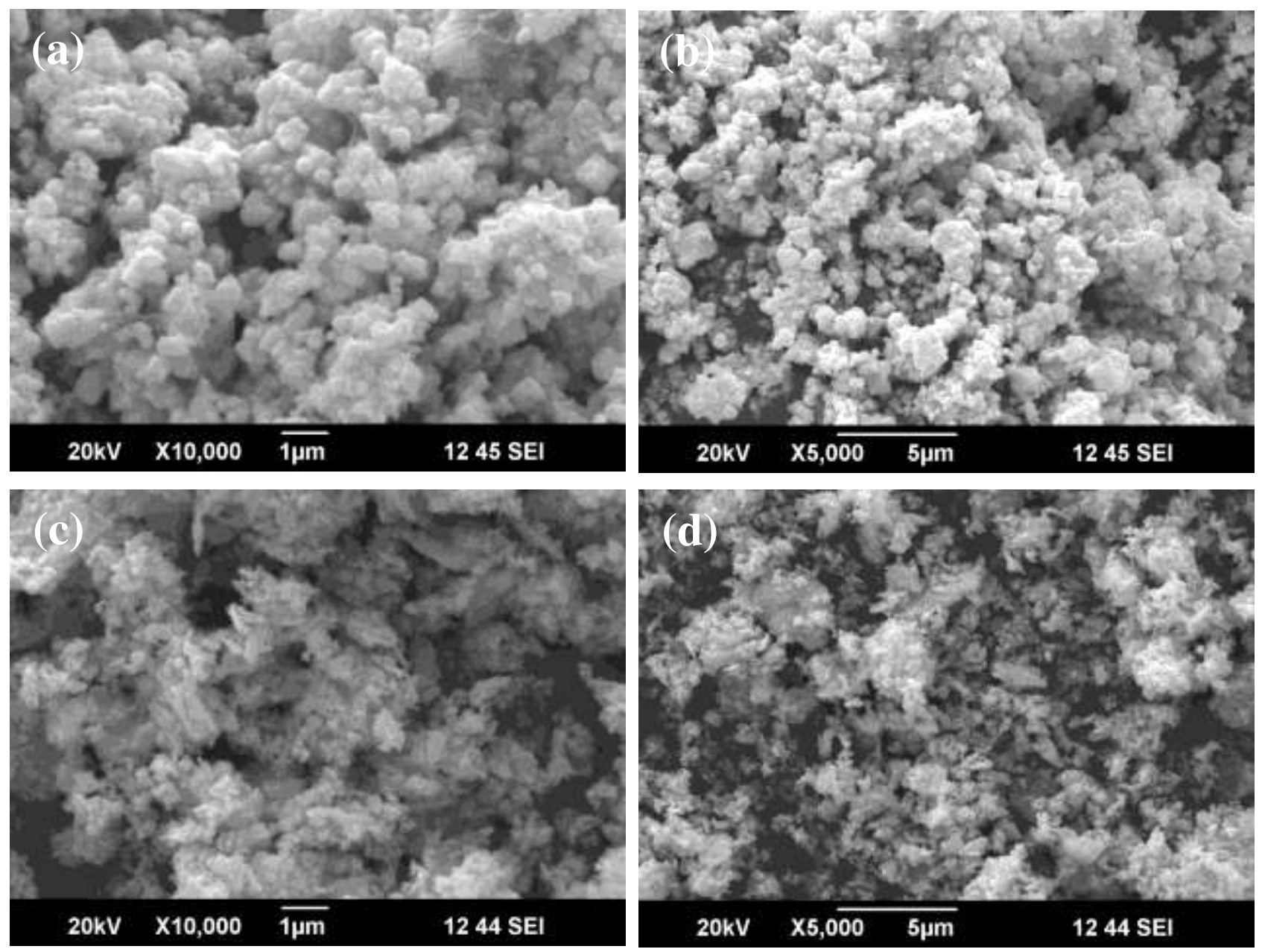

Fig.6 SEM images shows $\mathrm{CdO}$ nanostructure in presence of $0.1 \mathrm{M} \mathrm{NH}_{4} \mathrm{OH}(\mathrm{a \& b})$ and $\mathrm{NaOH}(\mathbf{c \& d})$.

To study the elemental composition of using SDBS surfactant with $\mathrm{CdO}$ nanostructures in presence of $0.1 \mathrm{M}$ strong and weak alkaline $\left(\mathrm{NaOH}\right.$ and $\left.\mathrm{NH}_{4} \mathrm{OH}\right)$ medium are shown in Fig.7(a-b). Here found the EDS results are shows the entry of $\mathrm{Cd}, \mathrm{O}$ and $\mathrm{Na}$ without any other impurities. Also expected data like mass $\%$ and atomic\% is inserted in Fig.7 $(a-b)$. 

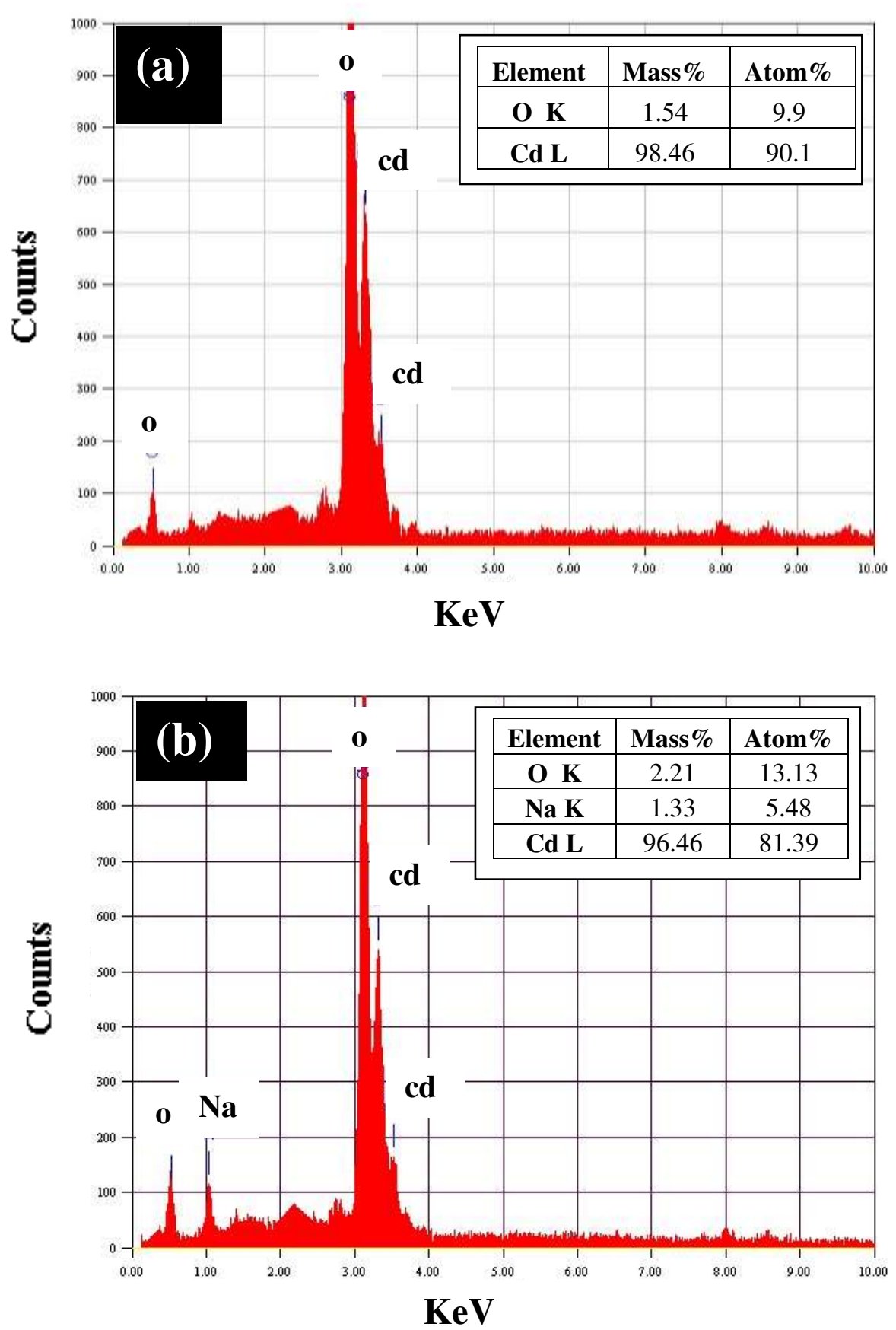

Fig.7(a-b): EDS spectrum of $\mathrm{CdO}$ nanostructure in presence of $0.1 \mathrm{M} \mathrm{NH} \mathrm{NH}_{4} \mathrm{OH}$ and $\mathrm{NaOH}$. 

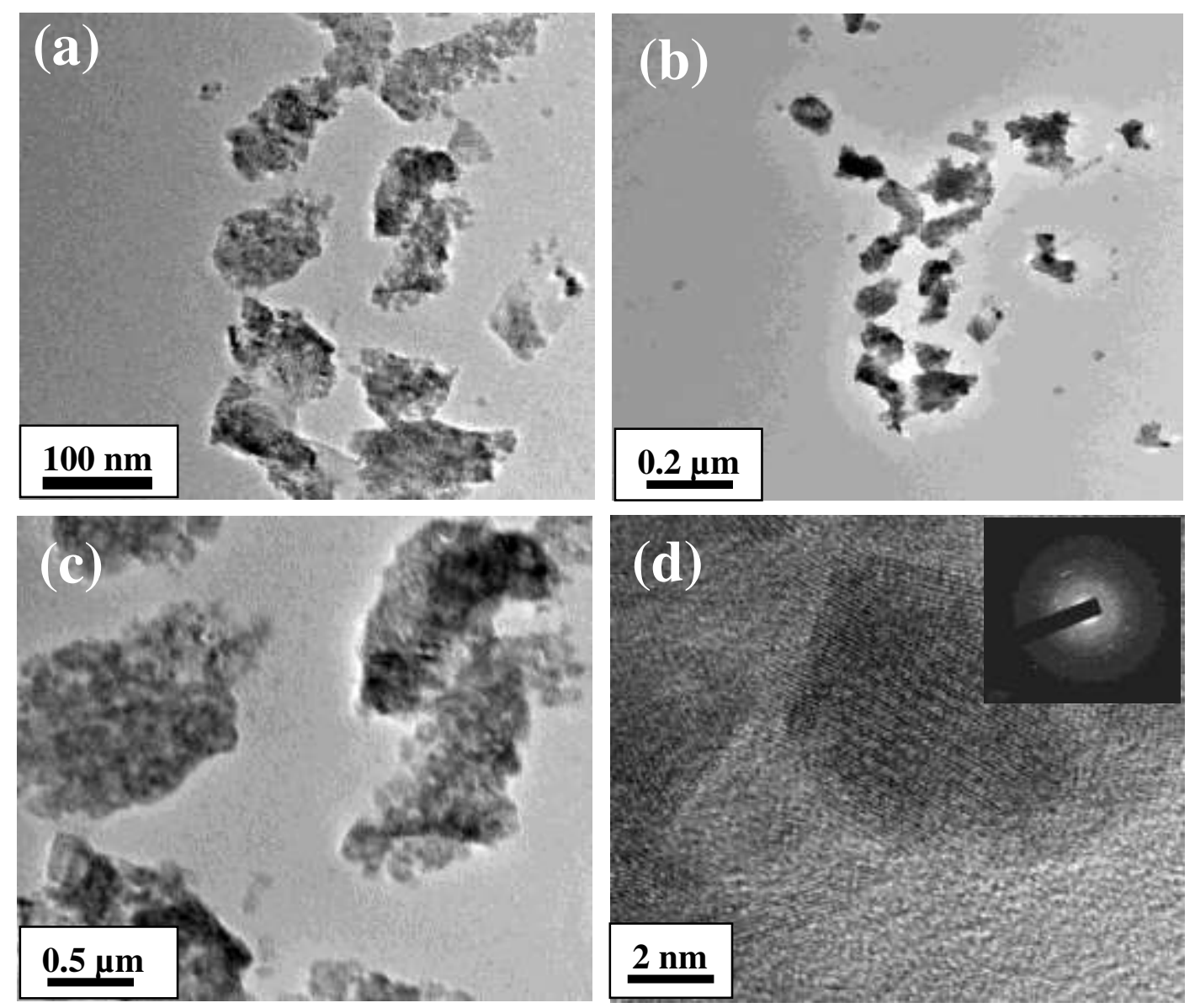

Fig.8(a-d): TEM, HRTEM micrographs and SAED pattern of CdO nanostrucrtures in presence of $0.1 \mathrm{M} \mathrm{NH} \mathrm{NH}_{4} \mathrm{OH}$.

Fig.8(a-d) shows the TEM, HR-TEM and SAED images of CdO nanostructure synthesized by adding $0.1 \mathrm{M} \mathrm{NH} \mathrm{NH}_{4} \mathrm{OH}$. In Fig.8(a-b) exhibits number of small particles placed on a single seat. These particles are slightly aggregated together. In presence of $0.1 \mathrm{M}$ $\mathrm{NH}_{4} \mathrm{OH}$, the particles are gradually become agglomerated nanorods, as shown in Fig.8(b). HRTEM was used to investigate the crystalline structure of agglomerates. The SAED pattern shows bright spots which confirms the presence of the crystalline phase of the cubic $\mathrm{CdO}$ nanostructures $[33,30]$. 

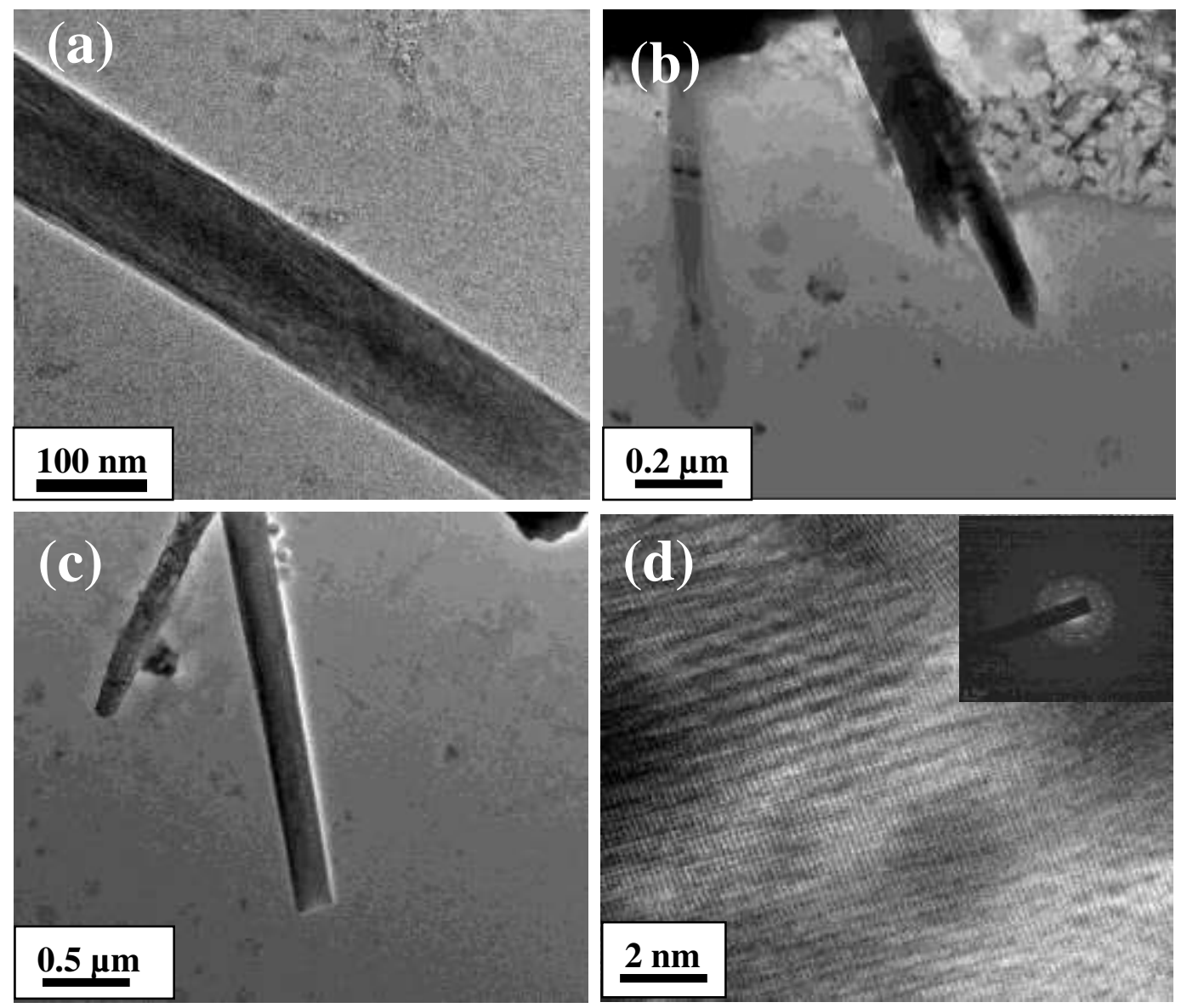

Fig.9(a-d): TEM, HRTEM micrographs and SAED pattern of CdO nanostrucrtures in presence of $0.1 \mathrm{M} \mathrm{NaOH}$.

Fig.9(a-c) shows the TEM images of CdO synthesized from microwave assisted synthesis using SDBS as surfactant with $0.1 \mathrm{M} \mathrm{NaOH}$. By comparison, it is found that with the appearance of SDBS surfactant, the uniform nanorods are clearer. The reason for this phenomenon may be $\mathrm{NaOH}$ ions enter the interior of $\mathrm{CdO}$, as well as $\mathrm{pH}$, plays an important role in the growth rate of $\mathrm{CdO}$ nanoparticles in presence of $0.1 \mathrm{M} \mathrm{NaOH}$, modifying directly or indirectly the kinetics of the growing process, and as a result the size, structure, crystallinity and morphology change from sphere to rod structure was observed using $\mathrm{NaOH}$ rather than $\mathrm{NH}_{4} \mathrm{OH}$. The diameter of nanorods range between $20-50 \mathrm{~nm}$ thick and length around $300 \mathrm{~nm}$. HRTEM image in Fig.9(d) shows they appear to be more compact, likely 
formed by highly interconnected nanorods, with respect to one seen on previous sample. SAED pattern reported in the inset of Fig.9(d), demonstrated that they are constituted by cubic $\mathrm{CdO}$ nanostructures highly crystalline [34].

The final morphology and crystal structure of nanosphere and nanorods were found to affect the spacing between crystalline orders. Varying the texture coefficient, dislocation density, specific surface area, X-ray density and grain size has direct effect on the morphology. The growth mechanism and its effect of $0.1 \mathrm{M}$ strong and weak alkaline medium as well as surfactant have also been discussed. As of our knowledge, very few reports on $\mathrm{CdO}$ nanostructures prepared using SDBS as a surfactant in presence of $\mathrm{NH}_{4} \mathrm{OH}$ and $\mathrm{NaOH}$ were produced by microwave irradiated wet chemical method. Here, the different morphology and microstructural value obtained from the present work is compared with literatures published elsewhere (Table 2). In this work we confirmed that the shape of nanostructure is stable as well as controllable super molecular structures and flexible physical properties due to the action of SDBS [35]. Also SDBS can proceed as exfoliation to intercalation, which means intercalation can expand the interlayer spacing of $\mathrm{CdO}$ material and exfoliation can break the van der waals force between the layers and external force together [36].

\subsection{Growth mechanism}

The growth mechanism of $\mathrm{CdO}$ nanostructures has been explained through four steps such as
a) Hydration,
b) Formation of intermediate,
c) Formation of metal hydroxide and
d) Formation of metal oxide. 
a) Hydration:

The cadmium and SDBS solutions were prepared by using double distilled water and the same were taken in equal proportion for the experiment as doublets. Here both the components are ionized in water such as cadmium acetate will ionized in to $\mathrm{Cd}^{2+}$ and $\mathrm{CH}_{3} \mathrm{COO}^{-}$ions. SDBS will ionized in to $\mathrm{Na}^{+}$and negatively charged SDBS derivate. Meanwhile $\mathrm{Cd}^{2+}$ will readily form an intermediate $\mathrm{n}\left[\mathrm{Cd}\left(\mathrm{H}_{2} \mathrm{O}\right)\right]^{2+}$.

b) Formation of intermediate:

i) In presence of strong alkaline medium:

When the initial $\mathrm{pH}$ of the above said a mixture is adjusted to 11.0 in presence of $\mathrm{NaOH}$, the $\mathrm{OH}-$ introduced in the mixture will interact with the intermediate $\mathrm{n}\left[\mathrm{Cd}\left(\mathrm{H}_{2} \mathrm{O}\right)\right]^{2+}$. and form unstable intermediate $\left[\mathrm{Cd}_{n}(\mathrm{OH})_{2 n}\left(\mathrm{H}_{2} \mathrm{O}\right)_{\mathrm{n}}\right]$, commonly known as olation [37]. The formation of unstable intermediate initiate the development of precipitate in the reaction mixture.

ii) In presence of weak alkaline medium:

The initial $\mathrm{pH}$ of the another mixture is adjusted to 9.0 in presence of $0.1 \mathrm{M} \mathrm{NH} 4 \mathrm{OH}$. Since $\mathrm{NH}_{4} \mathrm{OH}$ is weak base due to its low dissociation constant, the intermediate formation is slow process as compared with in presence of strong alkaline medium, It was confirmed that even after the complete stirring of the reaction mixture, the development of precipitate is very poor.

c) Formation of metal hydroxide:

When the $\mathrm{pH}$ of the mixture is attained at 11.0 and 9.0 , due the addition of $0.1 \mathrm{M}$ $\mathrm{NaOH}$ and $\mathrm{NH}_{4} \mathrm{OH}$, respectively in the reaction mixtures the excess $\mathrm{n}[\mathrm{OH}]^{-}$ions eliminate the 
$\mathrm{nH}_{2} \mathrm{O}$ molecules as its own ionic from the unstable intermediate $\left[\mathrm{Cd}_{n}(\mathrm{OH})_{2 n}\left(\mathrm{H}_{2} \mathrm{O}\right)_{n}\right]$ and produce $\mathrm{Cd}(\mathrm{OH})_{2}$ as precipitate. Simultaneously, the excess $\mathrm{OH}^{-}$ions from water molecule will reacts with $\mathrm{Na}^{+}$ions of SDBS and enhance the alkaline $(\mathrm{NaOH})$ nature in the reaction mixture and it helps to terminate the reaction with the formation of hydroxylated SDBS. It was observed that the final $\mathrm{pH}$ of $\mathrm{NaOH}$ and $\mathrm{NH}_{4} \mathrm{OH}$ added mixture were enhanced to 13.0 and 11.0 , respectively.

d) Formation of metal oxide:

The nown volume of neutral $\mathrm{pH}$ achieved final $\mathrm{Cd}(\mathrm{OH})_{2}$ residue is anneled at $300{ }^{\circ} \mathrm{C}$ to get the purest form of $\mathrm{CdO}$. The water molecules presrnt on $\mathrm{Cd}(\mathrm{OH})_{2}$ is completely dehydrated and the purest form of $\mathrm{CdO}$ obtained. From the morphological analysis it was observed that the strong alkaline medium develops nanorod shaped nano materials. It is mainly due to the step-by-step elimination of water molecule from the unstable intermediate. But in the case of weak alkaline medium the formation of perfect structure is retarded due to the presence weak electrolytic behaviour. Thus the morphological analysis simply shows the spherical shaped structure. The comparision of $\mathrm{CdO}$ nanoparticle development and its morphological structure changes mechanism reported in literature is shown in Table 2. 


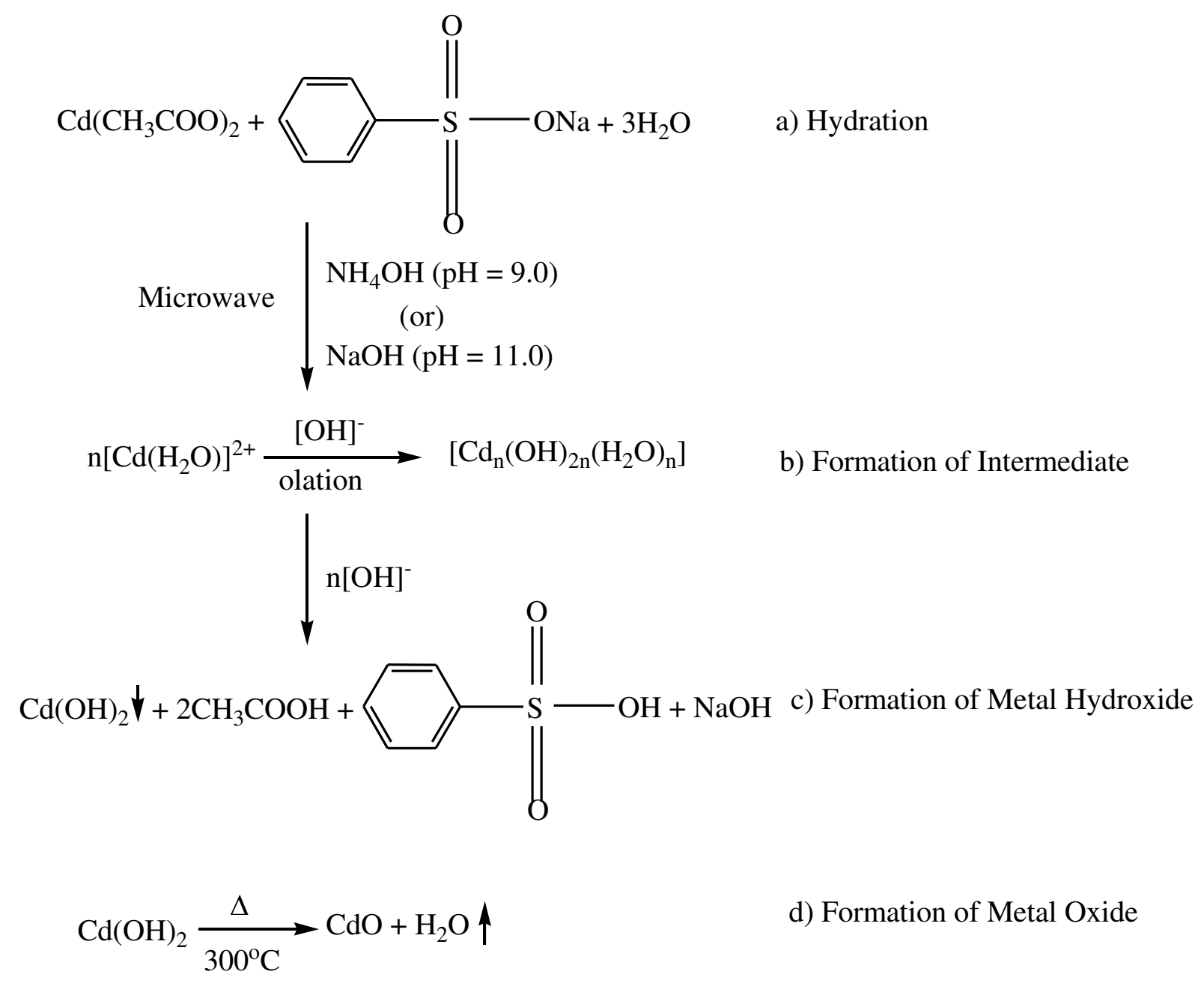


Table 2: Comparision of $\mathrm{CdO}$ nanoparticle development and morphological structures reported in literature.

\begin{tabular}{|c|c|c|c|c|c|c|c|}
\hline \multicolumn{3}{|c|}{ Component } & \multirow{2}{*}{$\begin{array}{c}\text { Growth } \\
\text { mechanism }\end{array}$} & \multirow{2}{*}{$\begin{array}{l}\text { Crystallite } \\
\text { size }(\mathbf{n m})\end{array}$} & \multirow{2}{*}{$\begin{array}{c}\text { Band gap } \\
(\mathrm{eV})\end{array}$} & \multirow{2}{*}{ Morphology } & \multirow{2}{*}{ Reference } \\
\hline Major & Additives & Reagent / pH & & & & & \\
\hline Cadmium chloride & - & $*$ & $*$ & $*$ & $*$ & Nanowires & {$[38]$} \\
\hline Cadmium acetate & PEG & $\mathrm{NaOH} / *$ & $*$ & 24.5 & $*$ & $*$ & [39] \\
\hline Cadmium nitrate & PEG & $*$ & $*$ & 25 & $*$ & Nanoparticles & {$[40]$} \\
\hline Cadmium chloride & - & Urea / * & $*$ & 65 & 3.75 & Spherical, rod & {$[41]$} \\
\hline Cadmium acetate & CTAB & Acetic acid /7.3 & $\dagger^{1}$ & 40 to 45 & 2.0 to 2.5 & Spherical & {$[42]$} \\
\hline Cadmium nitrate & - & $\mathrm{NaOH} / 11.0$ & $*$ & $*$ & $*$ & Nano disk & {$[43]$} \\
\hline Cadmium acetate & Glycine & $\mathrm{NH}_{3} / 12.0$ & $*$ & 12.6 & 2.35 & Nanoparticles & {$[44]$} \\
\hline Cadmium acetate & PEG & $\mathrm{NaOH} / 9.0$ & $*$ & 19.1 & $*$ & Spherical & [45] \\
\hline Cadmium chloride & $\begin{array}{l}\text { Triton } \\
\text { X100 }\end{array}$ & $\begin{array}{c}\mathrm{NaOH} \text { or } \mathrm{HCl} / \\
2.0 \text { to } 12.0\end{array}$ & $*$ & 50 & $*$ & Sphere & [46] \\
\hline Cadmium acetate & - & $\mathrm{NaOH} / *$ & $*$ & 25 & $\begin{array}{c}4.04 \text { to } \\
4.45\end{array}$ & $\begin{array}{l}\text { Plate like } \\
\text { structure }\end{array}$ & [47] \\
\hline Cadmium acetate & SDBS & $\mathrm{NH}_{4} \mathrm{OH} / 9.0$ & $\dagger^{2}$ & 54 & 1.8 & Spherical & Present work \\
\hline Cadmium acetate & SDBS & $\mathrm{NaOH} / 11.0$ & $\dagger^{2}$ & 60 & 2.0 & Nanorods & Present work \\
\hline
\end{tabular}

* Not reported; $\uparrow^{1}$ Micelle formation; $\dagger^{2}$ Four step mechanism 


\section{Conclusion}

Using microwave irradiation method, $\mathrm{CdO}$ nanostructures have been successfully synthesised using SDBS as a surfactant in presence of strong and weak alkaline medium. Uniformly synthesized $\mathrm{CdO}$ nanostructures clearly demonstrate that morphology and microstructures have been affected by the surfactant as well as alkaline medium. Crystalline nanorods have been developed in presence of strong alkaline medium due to step-by-step elimination of water molecule from the unstable intermediate and are found in elongated hierarchical nanostructures of a few microns in length. In order to synthesise standardized CdO nanorods for professional toxic gas sensors, this reported method can be used.

\section{Author contributions}

All authors discussed the experiment results and contributed to the writing of the paper.

\section{Data availability}

The data that support the findings of this study are available from the corresponding author upon reasonable request.

\section{Conflict of Interest}

The authors declare no conflict of interest.

\section{References}

[1] M.S. Chavali, M.P. Nikolova, SN Appl. Sci. 1, 1-30 (2019)

[2] R. Medhi, M.D. Marquez, T.R. Lee, ACS Appl. Nano Mater. 3, 6156-6185 (2020)

[3] D. Degler, U. Weimar, N. Barsan, ACS Sensors 4, 2228-2249 (2019)

[4] A. Cartwright, K. Jackson, C. Morgan, A. Anderson, D.W. Britt, Agronomy 10, 1-20 (2020)

[5] T. Prakash, G. Neri, A. Bonavita, E. Ranjith Kumar, K. Gnanamoorthi, J. Mater. Sci.: Mater. Electron. 26, 4913-4921 (2105) 
[6] H.L. Feng, W.Q. Wu, H.S. Rao, Q. Wan, L. Bin Li, D. Bin Kuang, C.Y. Su, ACS Appl. Mater. Interfaces 7, 5199-5205 (2015)

[7] D. Murugesan, K. Moulaee, G. Neri, N. Ponpandian, C. Viswanathan, Nanotechnology 30, 265501 (2019)

[8] T.Prakash, A.Bonavita, G.Neri, E.Ranjith Kumar, Superlattice Microst. 90, 117-123 (2016)

[9] T. Prakash, G. Neri, E. Ranjith Kumar, J. Alloys Compd. 624, 258-265 (2015)

[10] D. Sathya Raj, R. Jayaprakash, T. Prakash, G. Neri, T. Krishnakumar, Appl. Surf. Sci. 266, 268-271 (2013)

[11] M.H. Kim, Y.U. Kwon, J. Phys. Chem. C 113, 17176-17182 (2009)

[12] M. Burbano, D.O. Scanlon, G.W. Watson, J. Am. Chem. Soc. 133, 15065-15072 (2011).

[13] D. Sathya Raj, T. Krishnakumar, R. Jayaprakash, T. Prakash, G Leonardi, G Neri, Sens. Actuators B Chem.171, 853-859 (2012)

[14] K. Karthik, S. Dhanuskodi, C. Gobinath, S. Prabukumar, Mater. Res. Innov. 8917, 1$8(2018)$

[15] K. Kannan, D. Sivasubramanian, P. Seetharaman, Opt. - Int. J. Light Electron Opt. 204, 164221 (2020)

[16] B. Eigenmann, B. Scholtes, E. Macherauch, Mater. Sci. Eng. A 118, 1-17 (1989)

[17] D. Ariosa, F. Elhordoy, E.A. Dalchiele, R.E. Marotti, C. Stari, J. Appl. Phys. 110, $124901(2011)$

[18] U. Pal, S. Saha, B.K. Samantaray, A.K. Chaudhuri, H.D. Banerjee, Zeitschrift Fur Krist. - New Cryst. Struct. 193, 33-45 (1990)

[19] S. Balamurugan, A.R. Balu, K. Usharani, M. Suganya, S. Anitha, D. Prabha, S. Ilangovan, Pacific Sci. Rev. A Nat. Sci. Eng. 18, 228-232 (2016) 
[20] R. Mariappan, V. Ponnuswamy, P. Suresh, Superlattices Microstruct. 52, 500-513 (2012)

[21] D. Murugesan, S. Prakash, N. Ponpandian, P. Manisankar, C. Viswanathan, Colloids Surfaces A Physicochem. Eng. Asp. 569, 137-144 (2019)

[22] Z.R. Khan, M. Shkir, V. Ganesh, I.S. Yahia, S. AlFaify, Indian J. Phys. 13-18 (2020)

[23] J.R. Mohamed, C. Sanjeeviraja, L. Amalraj, J. Asian Ceram. Soc. 4, 191-200 (2016)

[24] E.F. Abo, I.A. Ibrahem, A. Mossad, W.A.A. Mohamed, Results Phys. 12, 562-570 (2019)

[25] S. Thanikaikarasan, T. Mahalingam, S.R. Srikumar, T. Kim, Y.D. Kim, S. Velumani, R. Asomoza, Adv. Mater. Res. 68, 44-51 (2009)

[26] J.A. Allen, D. Murugesan, C. Viswanathan, Superlattices Microstruct. 125, 159-167 (2019)

[27] K. Kaviyarasu, E. Manikandan, P. Paulraj, S.B. Mohamed, J. Kennedy, J. Alloys Compd. 593, 67-70 (2014)

[28] M.M. Hivrekar, D.B. Sable, M.B. Solunke, K.M. Jadhav, J. Non. Cryst. Solids. 474, $58-65(2017)$

[29] G. Somasundaram, J. Rajan, P.S.R. Dilip, J. Inorg. Organomet. Polym. Mater. 29, $1862-1873$ (2019)

[30] Z. Guo, M. Li, J. Liu, Nanotechnology 19, 245611 (2008)

[31] K. Anandhan, R. Thilak Kumar, Spectrochim. Acta - Part A Mol. Biomol. Spectrosc. 149, 476-480 (2015)

[32] L.-Z. Bai, F. Li, D. An, J.-F. Wei, Z.-Y. Zhang, Y.-Q. Liu, J. Nanosci. Nanotechnol. 18, 1804-1810 (2017)

[33] P. Thomas, K.E. Abraham, J. Lumin. 158, 422-427 (2015)

[34] S.T. Hossain, S.K. Mukherjee, Langmuir 28, 16614-16622 (2012) 
[35] S. Cao, T. Liu, W. Zeng, S. Hussain, Z. Wang, X. Peng, F. Pan, Nanosci. Nanotech. Let. 6, 1087 (2014)

[36] V. W. Lau, A. F. Masters, A. M. Bond, T. Maschmeyer, Chem. Eur. J. 18, 8230 (2012)

[37] Weidong Shi, Cheng Wang, Haishuni Wang, Hongjie Zhang, Cryst. Growth Des. 6, 915-918 (2006).

[38] X. S Peng, X.F Wang, Y.W Wang, C.Z Wang, G.W Meng, L.D Zhang, J. Phys. D: Appl. Phys. 35, L101-L104 (2002)

[39] Maryam Lashanizadegan, Hoda Mirzazadeh, J.Ceram. Process. Res. 13, 389-391 (2012)

[40] M. Tabatabaee, A. A. Mozafari, M. Ghassemzadeh, M. Reza Nateghi, I. Abedini, Bulg. Chem. Commun. 45, 90-92 (2013)

[41] A.K.Barve, S.M.Gadegone, M.R. Lanjewar, R.B.Lanjewar, International Journal on Recent and Innovation Trends in Computing and Communication. 2, 9 (2014).

[42] S. Pavithra, D. Balamurugan, R. Pandeeswari, B.G. Jeyaprakash, Superlattice Microst.75, 435-444 (2014)

[43] Pankaj Sharma, Dilbag Singh Rana, Ahmad Umar, Ramesh Kumar, Mohinder Singh Chauhan, Suvarcha Chauhan, Talanta. 153, 57-65 (2016)

[44] Raşit Aydin, Superlattice Microst.117, 46-56 (2018)

[45] P. Lokanatha Reddy, Kalim Deshmukh, K. Chidambaram, Basheer Ahamed, Kishor Kumar Sadasivuni, Deepalekshmi Ponnamma, Rajasekhar Lakshmipathy, Desagani Dayananda, S.K. Khadheer Pasha, Mater. Today- Proc. 9, 175-183 (2019)

[46] P.S. Geetha Malini, P. Durgadevi, N. Senthil Kumar, S. Rani, Mater. Today 11 September 2020 .

[47] C. Bhukkal, M.Chauhan, R.Ahlawat, Physica B. 582, 411973 (2020) 
Figures
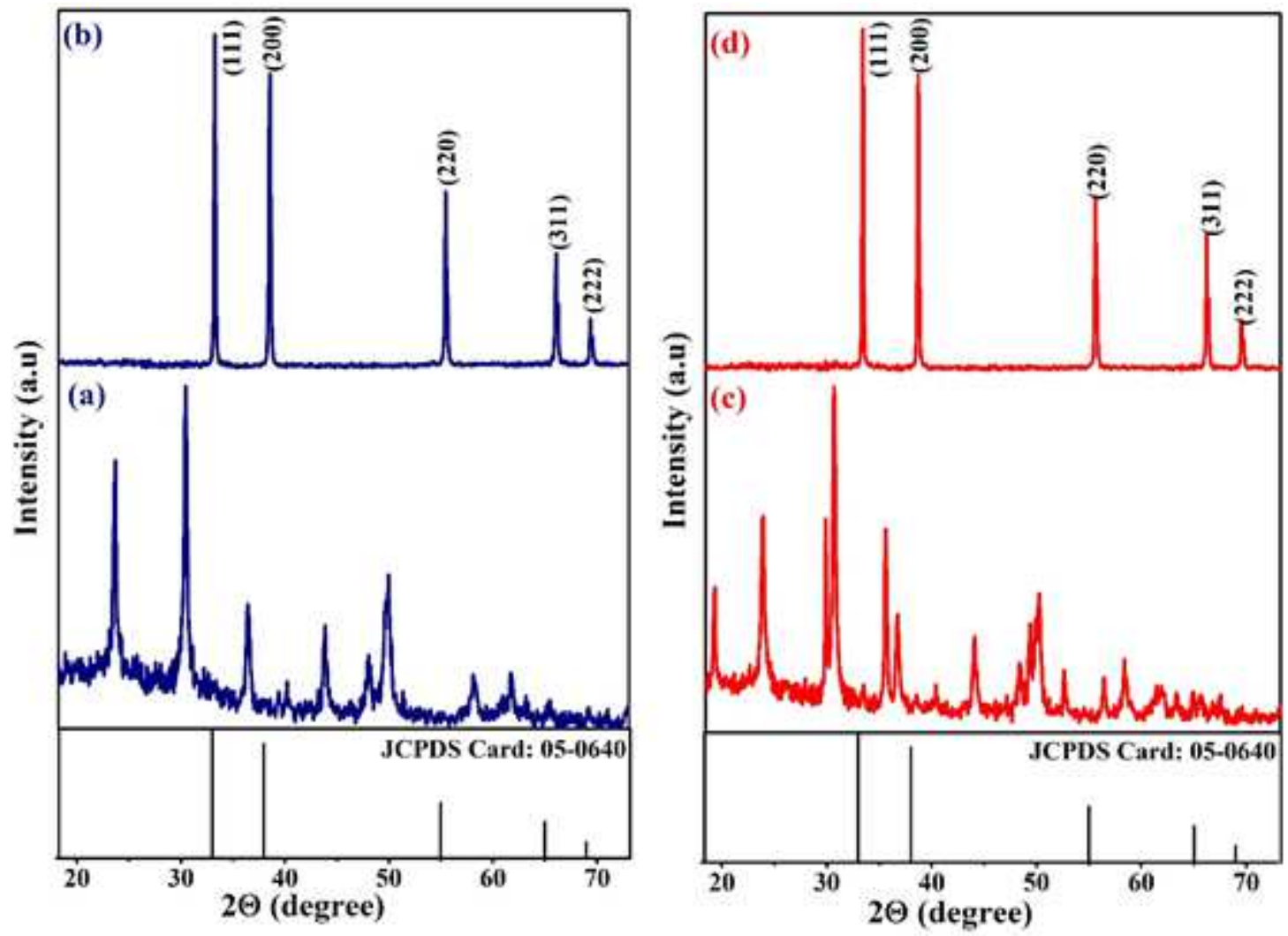

Figure 1

XRD pattern of $\mathrm{Cd}(\mathrm{OH}) 2$ inpresence of $0.1 \mathrm{M} \mathrm{NH} 4 \mathrm{OH}$ and $\mathrm{NaOH}(\mathrm{a} \& \mathrm{c})$ and $\mathrm{CdO}$ nanostructure inpresence of $0.1 \mathrm{M} \mathrm{NH} 4 \mathrm{OH}$ and $\mathrm{NaOH}(\mathrm{b} \& d)$.
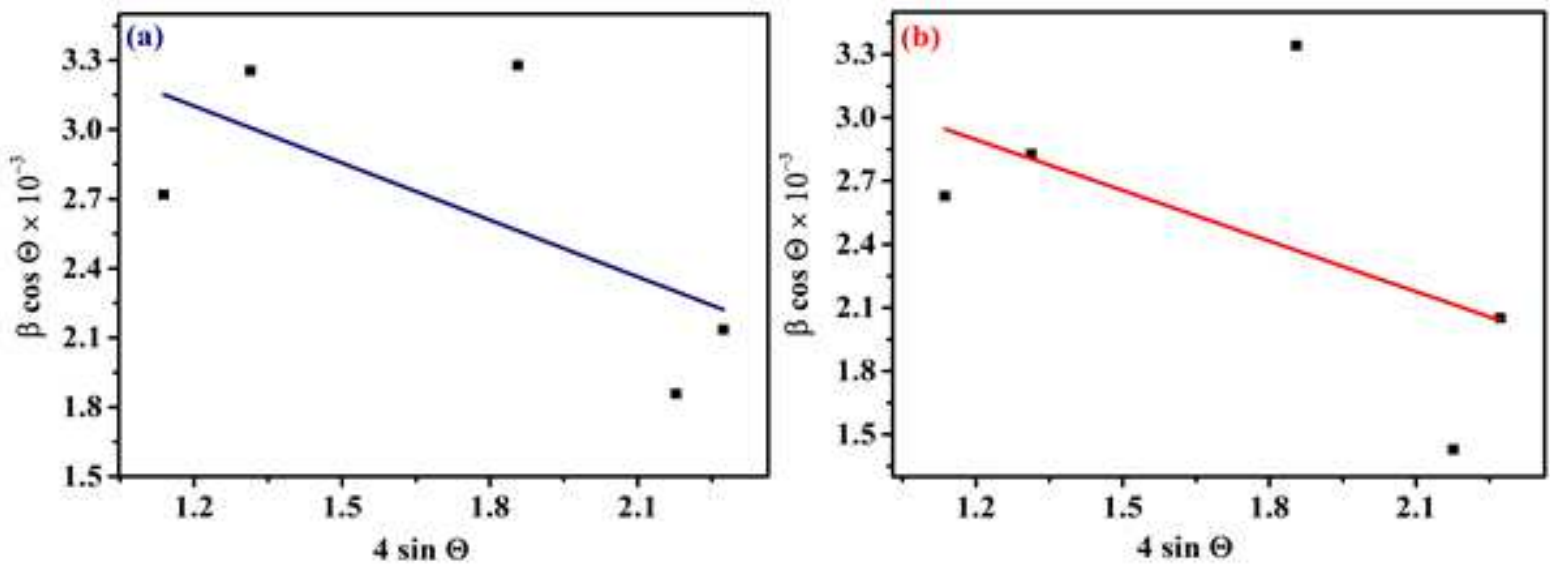

Figure 2

Williamson Hall Plot is indicating line broadening value due to the equipment of $\mathrm{CdO}$ nanostructure inpresence of $0.1 \mathrm{M} \mathrm{NH} 4 \mathrm{OH}$ and $\mathrm{NaOH}(a \& b)$. 

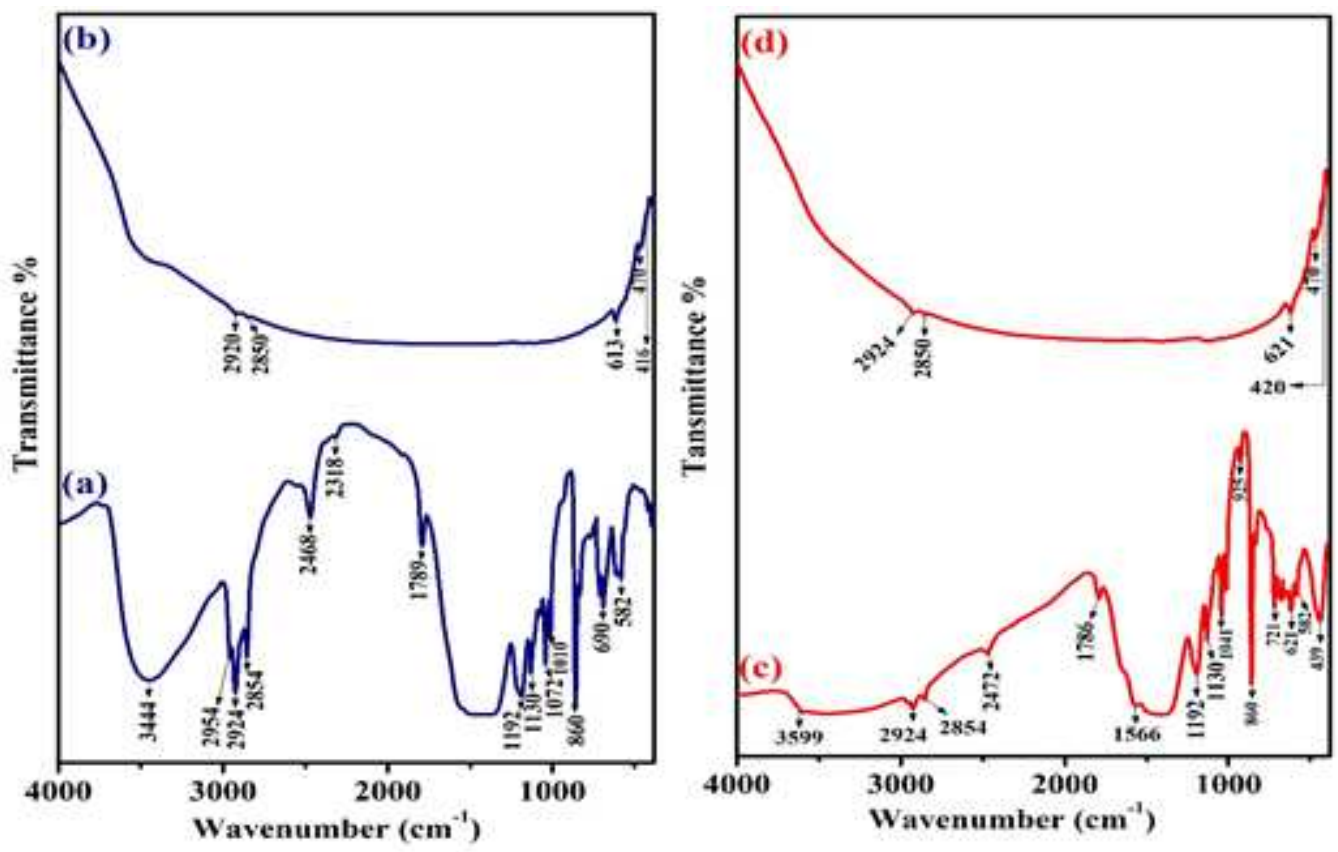

Figure 3

FTIR spectra of $\mathrm{Cd}(\mathrm{OH}) 2$ inpresence of $0.1 \mathrm{M} \mathrm{NH} 4 \mathrm{OH}$ and $\mathrm{NaOH}(\mathrm{a} \& \mathrm{c})$ and $\mathrm{CdO}$ nanostructure inpresence of $0.1 \mathrm{M} \mathrm{NH} 4 \mathrm{OH}$ and $\mathrm{NaOH}$ (b\&d). 


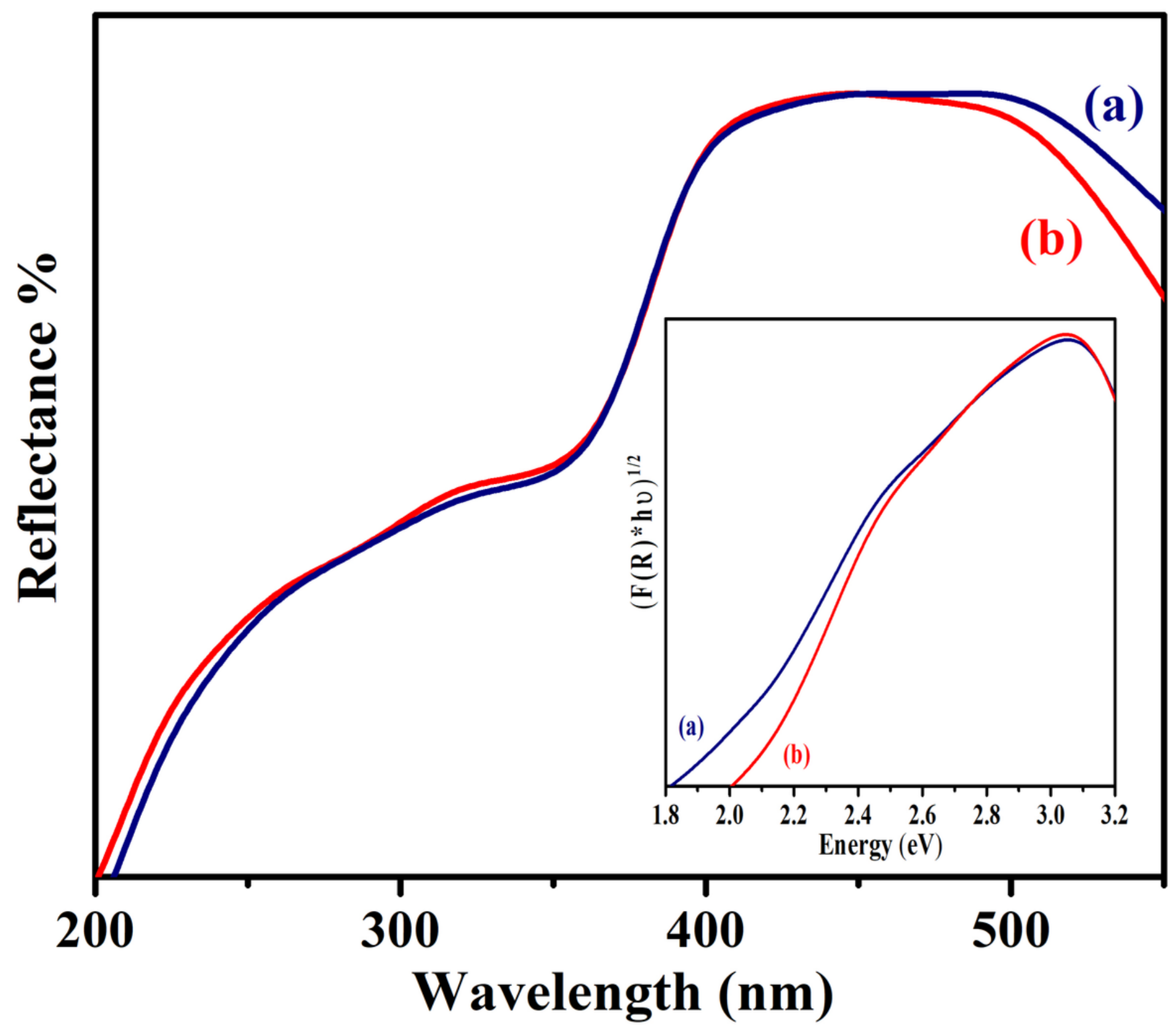

Figure 4

UV spectra of $\mathrm{CdO}$ nanostructure inpresence of $0.1 \mathrm{M} \mathrm{NH} 4 \mathrm{OH}$ and $\mathrm{NaOH}(a \& b)$. 


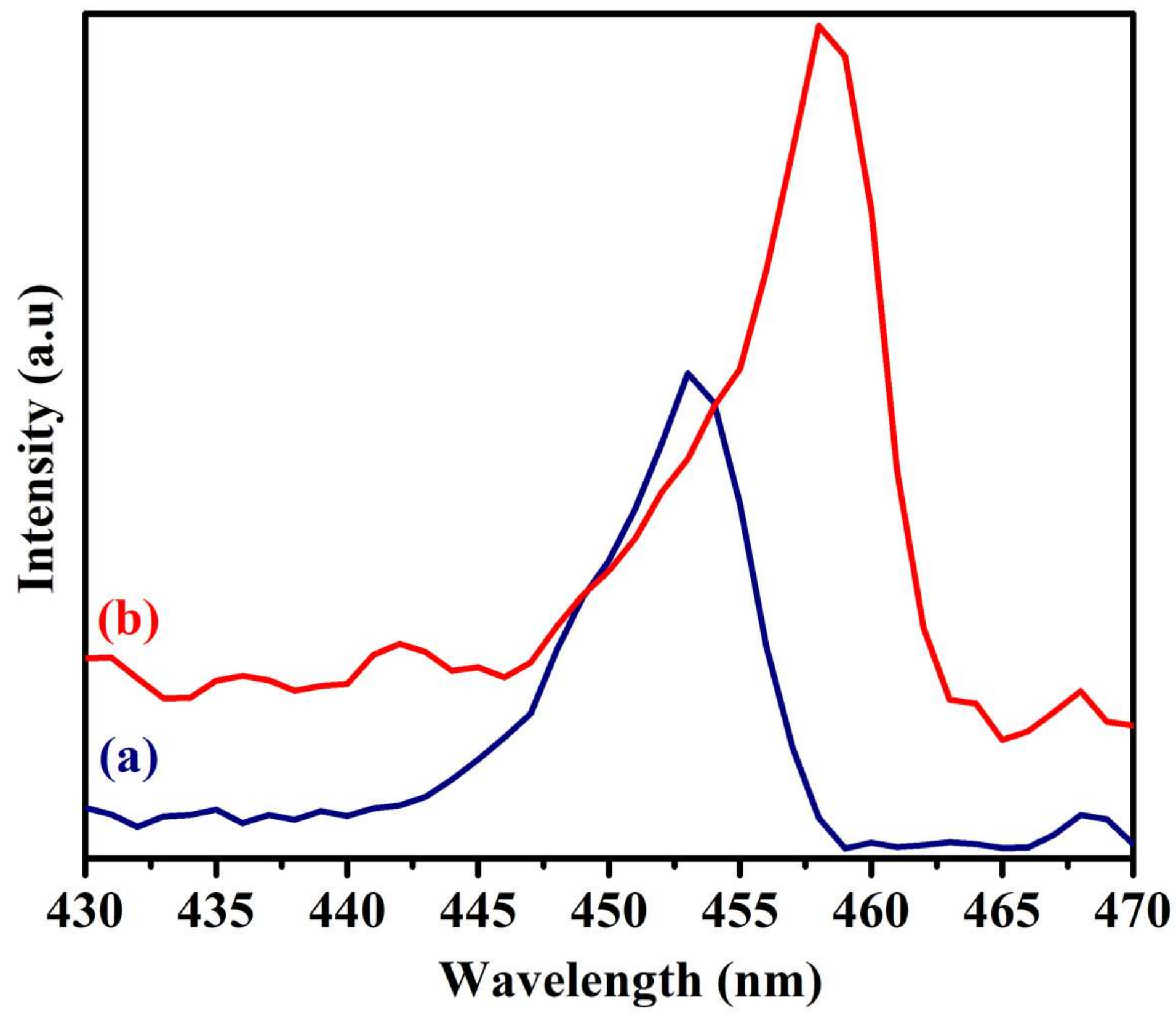

Figure 5

$\mathrm{PL}$ spectra of $\mathrm{CdO}$ nanostructure inpresence of $0.1 \mathrm{M} \mathrm{NH} 4 \mathrm{OH}$ and $\mathrm{NaOH}(\mathrm{a} \& b)$. 

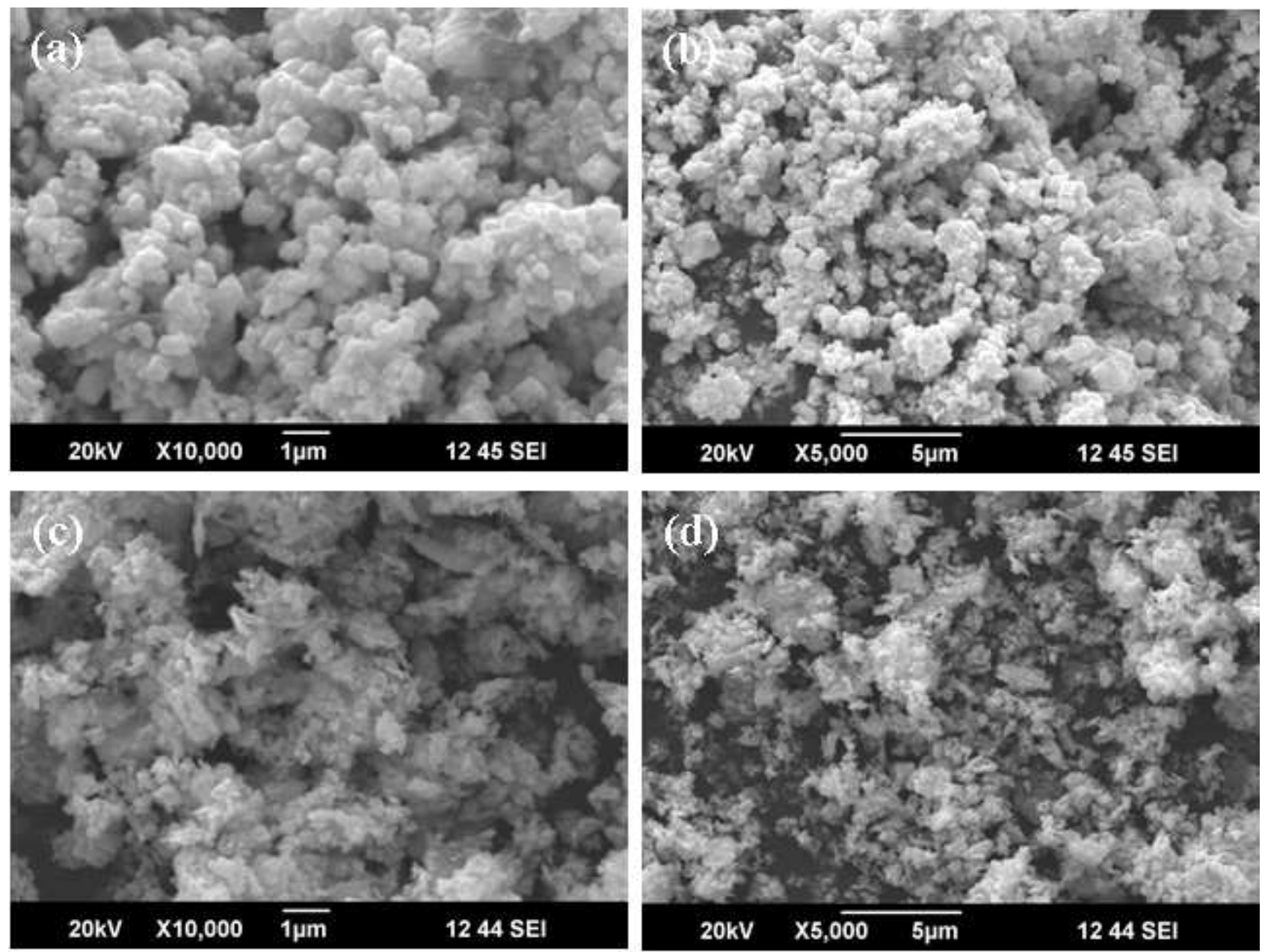

Figure 6

SEM images shows $\mathrm{CdO}$ nanostructure in presence of $0.1 \mathrm{M} \mathrm{NH} 4 \mathrm{OH}(a \& b)$ and $\mathrm{NaOH}(c \& d)$. 

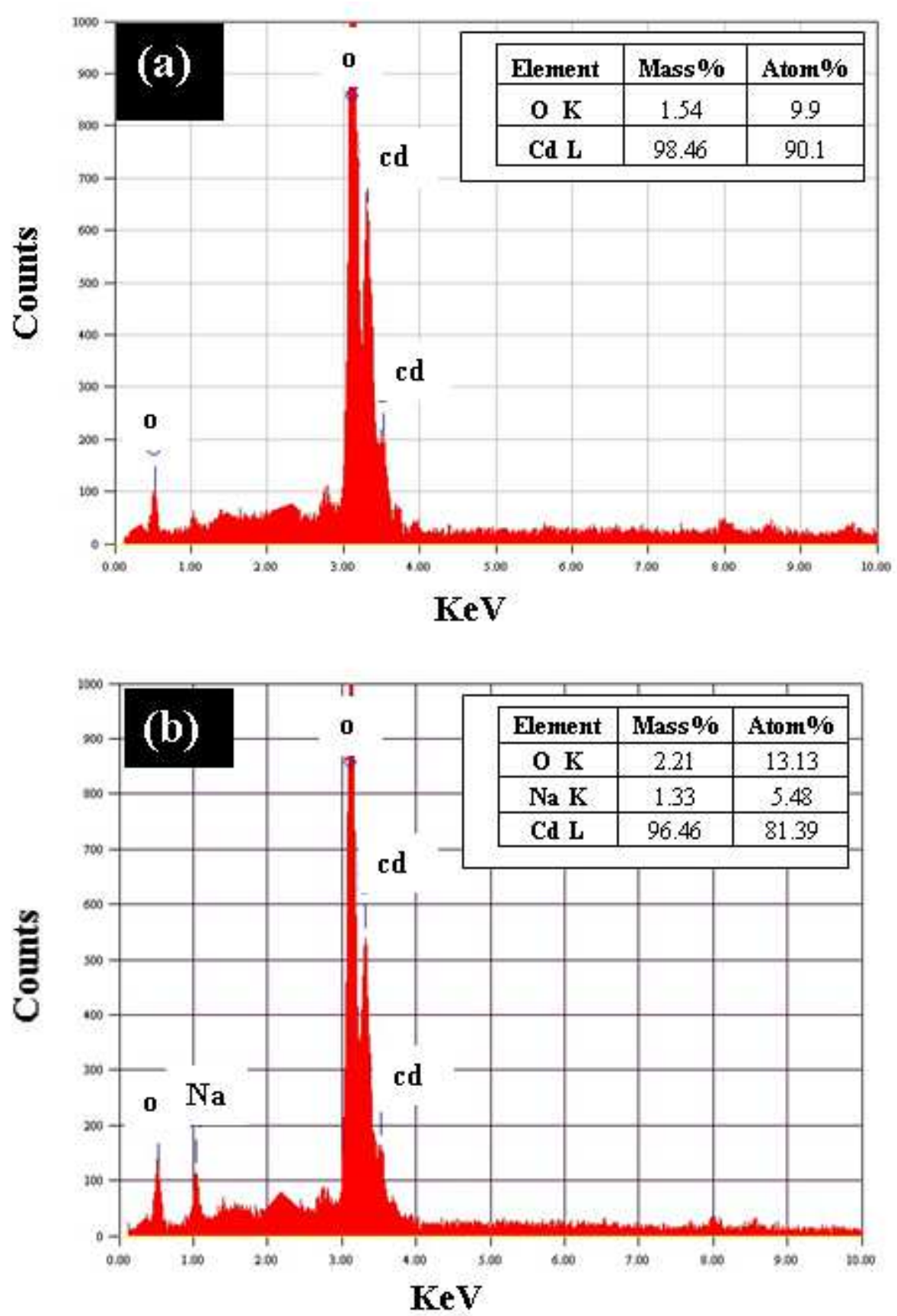

Figure 7

(a-b): EDS spectrum of $\mathrm{CdO}$ nanostructure in presence of $0.1 \mathrm{M} \mathrm{NH} 4 \mathrm{OH}$ and $\mathrm{NaOH}$. 

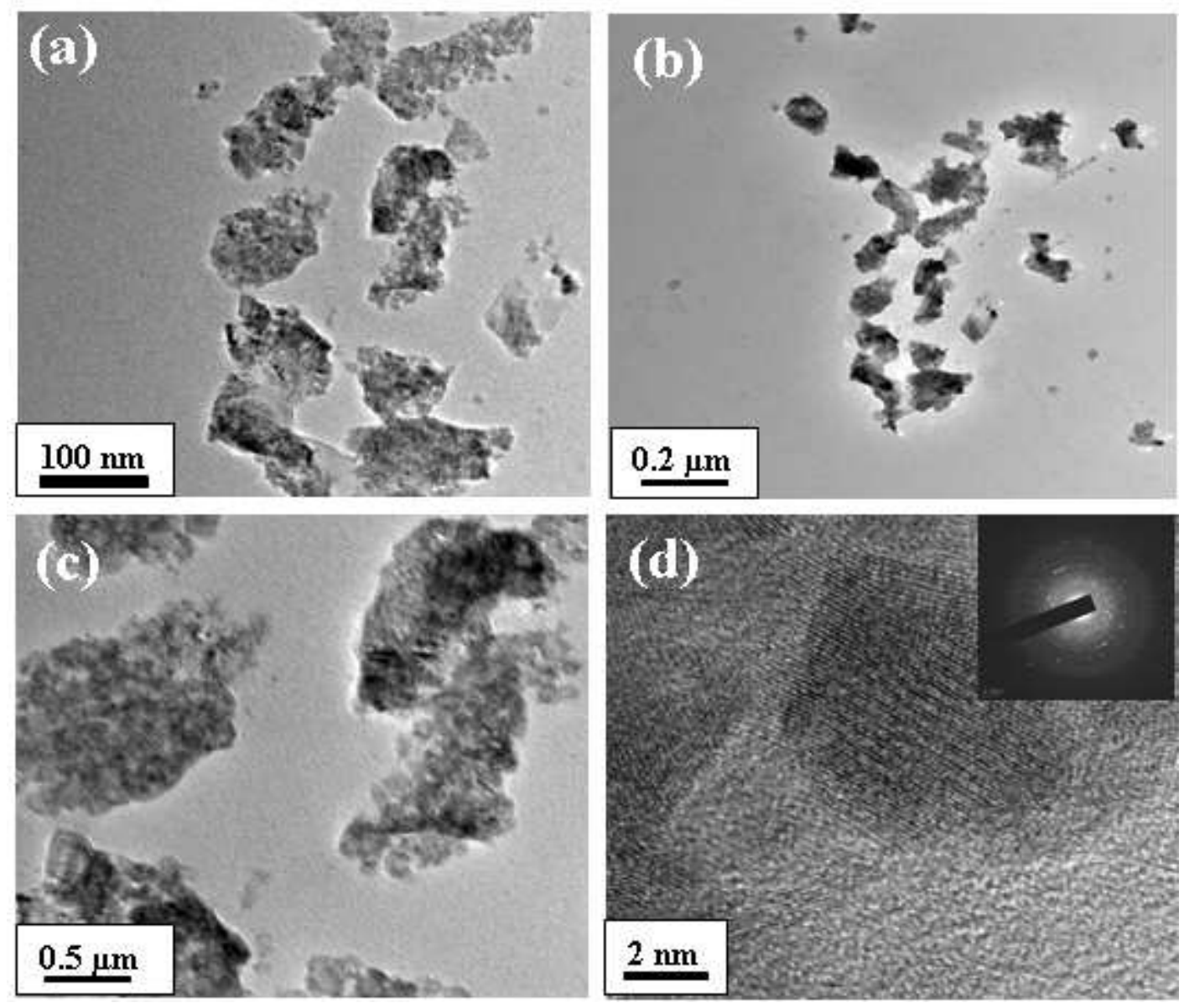

Figure 8

(a-d): TEM, HRTEM micrographs and SAED pattern of CdO nanostrucrtures in presence of $0.1 \mathrm{M} \mathrm{NH} 4 \mathrm{OH}$. 

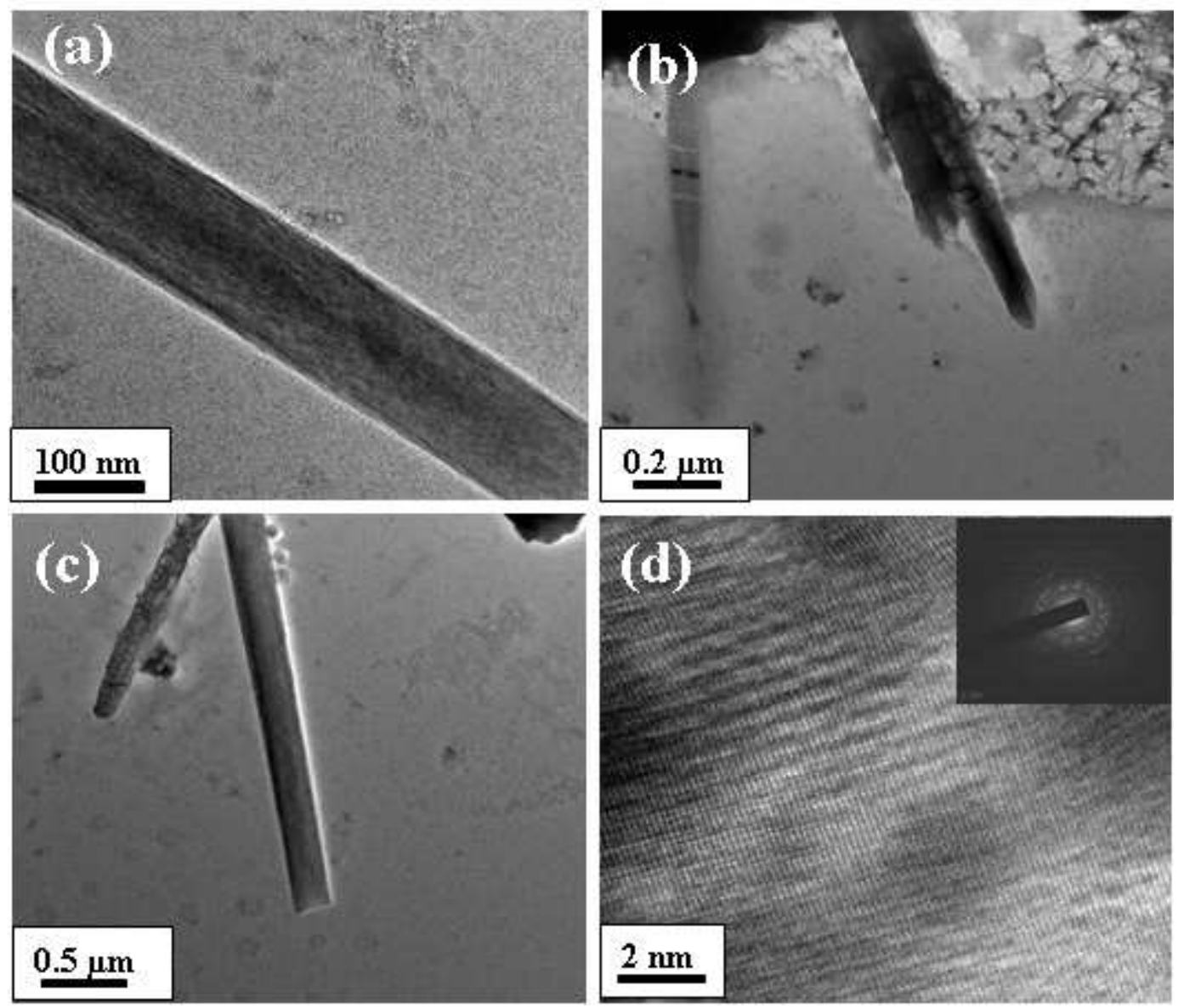

Figure 9

(a-d): TEM, HRTEM micrographs and SAED pattern of CdO nanostrucrtures in presence of $0.1 \mathrm{M} \mathrm{NaOH}$.

\section{Supplementary Files}

This is a list of supplementary files associated with this preprint. Click to download.

- Scheme01.png 